UNIVERSITÀ CATTOLICA DEL SACRO CUORE

Dipartimento di Economia e Finanza

\author{
Working Paper Series
}

Correlation of Brothers' Earnings and

Intergenerational Transmission

Paul Bingley

Lorenzo Cappellari

Working Paper n. 6

November 2013

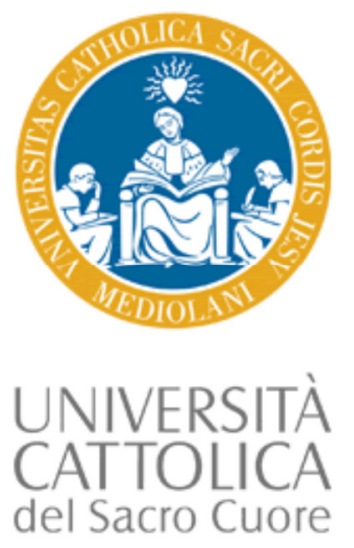




\title{
Correlation of Brothers Earnings and Intergenerational Transmission
}

\author{
Paul Bingley \\ SFI - The Danish National Centre for Social Research \\ Lorenzo Cappellari \\ Università Cattolica del Sacro Cuore
}

Working Paper n. 6

November 2013

\author{
Dipartimento di Economia e Finanza \\ Università Cattolica del Sacro Cuore \\ Largo Gemelli 1 - 20123 Milano - Italy \\ tel: +39.02.7234.2976 - fax: +39.02.7234.2781 \\ e-mail: dip.economiaefinanza@unicatt.it
}

The Working Paper Series promotes the circulation of research results produced by the members and affiliates of the Dipartimento di Economia e Finanza, with the aim of encouraging their dissemination and discussion. Results may be in a preliminary or advanced stage. The Dipartimento di Economia e Finanza is part of the Dipartimenti e Istituti di Scienze Economiche (DISCE) of the Università Cattolica del Sacro Cuore. 


\title{
Correlations of Brothers' Earnings and Intergenerational Transmission*
}

\author{
Paul Bingley \\ SFI - The Danish National Centre for Social Research \\ Lorenzo Cappellari \\ Department of Economics and Finance - Università Cattolica Milano
}

November 2013

\begin{abstract}
We model the correlations of brothers' earnings isolating the effect of fathers' earnings from additional residual influences shared between brothers. We separate the two effects by analysing sibling correlations and intergenerational correlations jointly within a unified framework. Our multi-person model of earnings dynamics distinguishes permanent from transitory shocks, allows for heterogeneous life cycle effects and nests previous models. Using data on the Danish population of father/first-son/second-son triplets, we corroborate the findings of studies that do not account for life cycle effects for those aged in their 30's, but find correlations twice as large at 25. The impact of intergenerational effects also varies over age, but is everywhere higher than found in previous studies -by on average a factor of thirteen - and accounts for most of the sibling correlation. We provide evidence that lack of both life cycle effects and heterogeneous intergenerational transmission across families in previous studies explain the difference. When allowing for differential intergenerational transmission within families, we find mild evidence of stronger transmission to second sons.
\end{abstract}

Keywords: Sibling correlations; Intergenerational transmission; Life cycle earnings JEL codes: D31, J62

\footnotetext{
"We thank Anders Björklund, Mette Ejrnæs, Bo Honorè, Matthew Lindquist, Bash Mazumder, Costas Meghir, Claudia Olivetti, Luigi Pistaferri, Gary Solon and audiences at Copenhagen Business School, University of Copenhagen, the University of Milan, La Sapienza University in Rome, ZEW-Mannheim, the $3^{\text {rd }}$ LEED Workshop, ICEEE 5 ${ }^{\text {th }}$, EEA 2013, ESPE 2013 and EALE 2013 for their comments. Cappellari gratefully acknowledges the hospitality of SFI in Copenhagen. A previous version of this paper was circulated as IZA DP 6987 and CESIfo WP 3994. Financial support was provided by the Danish Strategic Research Council (DSF-09065167). The usual disclaimers apply. Addresses for correspondence: Bingley, SFI, The Danish National Centre for Social Research, Herluf Trolles Gade 11, DK-1052, Copenhagen, pbingley@sfi.dk; Cappellari, Department of Economics and Finance, Università Cattolica Milano, Largo Gemelli 1 I-20123 Milano, lorenzo.cappellari@unicatt.it.
} 


\section{Introduction}

Explaining inequality of individual outcomes on the basis of family background is the subject of a vast literature in economics, sociology and other disciplines. The theoretical background in economics for the analysis of family effects dates back to the contributions of Becker and Tomes (1979). In their model, parents care about the lifetime earnings of their children and maximize utility by choosing between own consumption and investment in child earnings capacity. Offspring outcomes depend also on other productive endowments which are transmitted through the generations. As a result, lifetime earnings are transmitted intergenerationally, through parental incomes and productive endowments. Solon (1999), Björklund and Jännti (2009) and Black and Devereux (2011) document the progress made by economists in this field over the past twenty years, illustrating various angles from which one can look at the importance of family background. Among these, intergenerational and sibling studies represent two prominent research approaches: the first explicitly considers the parentchild transmission, while the second provides an omnibus measure of family and community influences on offspring outcomes.

How much of the correlation in sibling outcomes is due to intergenerational transmission? Answering this question is key for understanding the channels through which outcomes are transmitted within the family and informing scope for policy interventions. Yet, a direct empirical answer to this question is still missing in the literature. This paper provides such an answer by developing an econometric model of intergenerational and sibling correlations in life cycle earnings.

We provide two main contributions to the literature. This is the first paper that studies intergenerational and sibling correlations of earnings jointly within a unified framework. We draw data from administrative registers of the Danish population and model earnings dynamics within father/first-son/second-son triplets. Using these triplets provides identification of intergenerational effects separately from residual sibling effects within the overall sibling correlation. Our model nests the ones of previous research that have focussed either on intergenerational or sibling correlations. The siblings and intergenerational approaches have complemented each other over the past twenty years, although indirectly. With a focus on permanent incomes, Solon (1999) shows analytically how the sibling correlation can be decomposed into a part due to intergenerational transmission and a residual sibling effect, the latter being interpreted as "...the combined effect of family background characteristics uncorrelated with parental income..." (Solon, 1999, page 1776). Subsequent research has been using this decomposition in calibration, by combining statistics of 
intergenerational and sibling associations estimated for different families and from separate studies. Other researchers have provided answers to this question by estimating the sibling correlation before and after integrating out the effect of parental permanent earnings from sons permanent earnings (Mazumder, 2008; Björklund et al., 2010). In both cases, intergenerational transmission is assumed homogeneous in the population. Instead, in this paper we provide a direct decomposition of sibling correlations that allows for intergenerational links to differ across families. In this way, we estimate the importance of parental earnings to be much larger than has been found in previous research, by a factor of thirteen.

Our second contribution is to bring together insights from the sibling and intergenerational literatures with the literature on individual earnings dynamics. The seminal works of Lillard and Willis (1978), Lillard and Weiss (1979), Hause (1980) and MaCurdy (1982) initiated a long tradition of studies of individual earnings dynamics, surveyed in Meghir and Pistaferri (2011). Moffitt and Gottschalk (1995) have pioneered the use of these models for analysing trends in earnings inequality, opening up a stream of empirical research on the evolution of permanent and transitory components of earnings inequality. For the first time we apply this approach to the analysis of earnings dynamics of fathers, sons and siblings. ${ }^{1}$ Our model allows for individual heterogeneity in earnings growth and serially correlated transitory shocks. In this way we are able to tackle life cycle biases and transitory shocks, which are the estimation issues plaguing the study of intra-family earnings correlations. Previous studies have dealt with these issues either taking averages of individual earnings over several points-in-time to integrate out transitory shocks or limiting the analysis to a specific age range to mitigate life cycle biases. Both approaches entail a loss of information. Furthermore, there is a tension between the two approaches in that the time interval required for integrating out shocks of even moderate persistence is longer than the one in which the life cycle bias is considered minimized. ${ }^{2}$ We take an entirely different route and model both sources of bias, which enables us to avoid informational losses and to show how intergenerational and siblings correlations evolve fromages 25 to 48-60.

Using data on individual earnings averaged between age 25 and 42, previous research for Denmark has estimated the sibling correlation of permanent earnings to be around 0.23

\footnotetext{
${ }^{1}$ The one study of multi-persons earnings dynamics that we are aware of is Ostrowsky (2012), who analyzes spouses' earnings in Canada. He builds on the earlier work of Hyslop (2001) who modeled the covariance structure of spouses' earnings in the US, but without allowing for life-cycle effects. See also Blundell et al. (2012) for a life-cycle model of spouses earnings, labor supply and consumption.

${ }^{2}$ Observing earnings for the full working life of two generations would obviously mitigate life-cycle biases. In our data we are able to observe at most 32 years of earnings for fathers and 27 years of earnings for sons.
} 
(Björklund et al., 2002). While confirming this finding on average, our results show that such correlation varies considerably over the life cycle, being about 0.5 at age 25 , dropping to 0.15 by the mid-30s, and then rising again to 0.23 by age 48 . The $u$-shaped life cycle pattern of the sibling correlation reflects the existence of Mincerian cross-overs of earnings profiles within birth cohorts: there is a negative association between starting earnings and earnings growth across individuals, so that the intra-generational distribution of permanent earnings first shrinks and then fans out over the life cycle. We find that the compression/decompression occurs through the earnings component shared by siblings, generating a u-shaped pattern of sibling correlations.

We find that intergenerational associations play a major role in determining the sibling correlation of permanent earnings; also, they display less life cycle variation compared with the overall correlation. Our results indicate that intergenerational factors account for about 60 per cent of the overall sibling correlation at age 25; this share rises to 90 per cent towards the mid-30s, and decreases to two thirds by the late-40s. On average, the intergenerational component accounts for 80 per cent of the overall correlation. These results differ from those of previous studies that have implemented indirect decompositions, finding that in the Nordic countries the share of sibling earnings correlation accounted for by intergenerational factors is about 10 per cent ( 6 per cent for Denmark).

Our model nests the ones of previous studies and we can exploit this property to provide further insights on our main results. The first nested model is without life cycle variation of permanents earnings, a feature that also underlies the decomposition formula used by existing research. We find that in the model without life cycle effects the intergenerational component accounts for 60 per cent of the sibling correlation, which is closer to previous estimates for Denmark than our estimates from the main model. This suggests that the inclusion of life cycle effects partly explains the differences between ours and others' results. Secondly, we estimate a version of the model that only accounts for intergenerational effects and ignores residual sibling components. Comparing the predicted intergenerational effect between this and the full model is informative on the existence of correlation between intergenerational and residual sibling effects, something that we exclude when estimating the main model. We show that there are only minor significant differences in predictions between the full and the nested model, and that these are concentrated at young ages. Finally, our model nests a sibling-only model. We estimate this only using data on brothers and show that the predicted overall sibling correlation from this model matches the one from the main model. 
To further benchmark our findings with non-nested models, we use our data to replicate the approaches followed by previous studies, calibrations and sequential conditioning on fathers' earnings. For both approaches we find that fathers permanent earnings account for only 3 per cent of the sibling correlation. However, we show that it is enough to allow the intergenerational elasticity in these models to be heterogeneous across families to increase the share 6-9 fold. Heterogeneity of intergenerational transmission is fully accounted for in our multi-person model of earnings dynamics, which can explain the different conclusions we reach compared with the other approaches.

In the last part of the paper we consider how the results vary when there are sisters (with the same legal mother and father) in the family; in addition, we develop a variant of the model in which the extent of intergenerational transmission is allowed to differ between brothers. We find that intergenerational transmission is stronger in the absence of sisters and to second sons, although in both cases the differences become statistically insignificant after age 30 .

\section{Related literatures}

\subsection{Sibling studies}

Research on sibling correlations in outcomes has a long tradition in the economic and sociological literatures, see the reviews in Griliches (1979), Solon (1999), Björklund and Jännti (2009) and Black and Devereux (2011). Siblings are “...more alike than a randomly selected pair of individuals on a variety of socioeconomic measurements..." (Griliches, 1979; page S38); sibling correlations of earnings or other outcomes have been used in the literature as a way to capture many of the influences that are shared by siblings. These may originate from the intergenerational transmission of outcomes, but may also stem from other factors passed from parents to children that are (at least partly) independent of parental outcomes, such as values (Behrman et al., 1982). In addition, sibling effects capture those influences that are shared by siblings but do not come from the parents, such as orthogonal school or community effects. On the other hand, there may be factors transmitted within the family that are not shared by siblings, say because of differential treatment from parents, which are not captured by sibling correlations.

The prototypical earnings model used by previous research on sibling correlations specifies individual log earnings $(w)$ as the sum of three orthogonal components:

$$
w_{i j t}=a_{i j}+f_{j}+v_{i j t}, \quad a_{i j} \sim(0, \operatorname{var}(a)), f_{j} \sim(0, \operatorname{var}(f)), v_{i j t} \sim(0, \operatorname{var}(v))
$$


where $i$ indexes individuals, $j$ indexes families and $t$ indexes time, see e.g. Solon (1999) and Björklund et al. (2009). ${ }^{3}$ The $a$ and $f$ components are assumed time invariant and measure permanent earnings, whereas $v$ is a transitory shock typically assumed white noise. ${ }^{4}$ Permanent earnings depend on an individual-specific factor $a_{i j}$ capturing idiosyncratic components of permanent earnings, and on a family-specific one $f_{j}$ absorbing all determinants of permanent earnings that are shared by siblings, including both intergenerational transmission and all other sources of sibling similarities in earnings; we will refer to the latter as residual sibling effects. Intergenerational earnings transmission may depend on endowments passed on at birth or on the extent with which fathers are able to transmit their skills and preferences to their sons after birth. Residual sibling effects, on the other hand, include paternal influences not captured by earnings transmission, shared maternal influences, as well as other community effects shared by siblings that are independent of the parents. Schools, friendship networks or other influences operating at the community level are examples of residual sibling effects. We will refer to the effects captured by $f_{j}$ (intergenerational plus residual sibling) as overall sibling effects.

The two components of permanent earnings are drawn from unspecified distributions with variances $\operatorname{var}(a)$ and $\operatorname{var}(f)$. The sibling correlation of permanent earnings $\left(r^{S}\right)$ is the ratio between the variance of the sibling component and the total variance of permanent earnings:

$$
r^{S}=\frac{\operatorname{var}(f)}{\operatorname{var}(a)+\operatorname{var}(f)}
$$

The sibling correlation provides an omnibus measure of family and community effects, namely the share of inequality in permanent earnings accounted for by family and community background. Identification of the sibling correlation is achieved when data are available on earnings for sibling pairs over multiple years, the multi-year requirement enabling separation of permanent from transitory earnings. Existing studies report estimates of the correlation in brothers' permanent earnings ranging from $0.4-0.5$ in the US (Solon et al., 1991; Altonji and Dunn, 1991; Solon, 1999; Mazumder, 2008) to a little higher than 0.3 in Sweden (Björklund

\footnotetext{
${ }^{3}$ It is typical to "residualize" earnings on some common age or time trend or other observables, so that equation (1) is better understood as a model of individual deviations from the mean.

${ }^{4}$ One exception is Björklund et al., 2009, who adopt a stationary AR(1) process.
} 
et al., 2009) and about 0.2 for Norway and Denmark (Björklund and Jännti, 2009), meaning that between one fifth and one half of the dispersion of permanent earnings is due to betweensibling differences in income generating factors and the remainder is due to differences within sibling pairs.

Understanding how much of the sibling correlation is in fact mirroring intergenerational transmission is important both for understanding the mechanisms behind between-family differences in the distribution of outcomes and for gauging of the scope for inequalityreducing policies implemented at the community level. A formal characterization of the link between sibling income correlation and the intergenerational income elasticity (IGE, the slope coefficient of a regression of sons' log incomes on fathers' log incomes) is provided by Solon (1999). He starts with the model of equation (1) and writes the sibling component as a function of father's permanent income and a residual sibling effect orthogonal to father's income, capturing remaining shared factors independent of father's income. The IGE is specified as constant in the population. Assuming stationarity in the distribution of permanent incomes of both fathers and sons, the resulting decomposition of the sibling correlation is:

$$
r^{S}=I G E^{2}+\text { residual sibling correlation }
$$

Solon (1999) reports an IGE of 0.4, which matched to a sibling correlation of about the same size implies that 40 per cent $\left(=0.40^{2} / 0.40\right)$ of the sibling correlation can be ascribed to intergenerational transmission. Subsequent research has been applying this decomposition indirectly as a calibration on the basis of sibling correlations and IGEs sometimes estimated from different families and different samples, finding in general a small effect for intergenerational factors. For Denmark, Björklund and Jännti (2009) report an IGE of about 0.12 and a brother correlation of about 0.23 , obtaining that in Denmark the role of parental income is negligible, explaining 6 percent of the overall sibling correlation. One of our contributions to the literature is to provide a counterpart of this decomposition that allows for intergenerational transmission to be heterogeneous in the population, which we achieve by developing a model of the joint earnings dynamics of fathers and sons.

Björklund and Jännti (2012) use Swedish register data and apply the sibling correlation model to a range of traits and outcomes such as IQ, non-cognitive skills, height and years of schooling, as well as long-term earnings. They find that sibling correlations in earnings are the lowest, and that the strongest associations characterize height and IQ. They also estimate intergenerational correlations and apply the decomposition formula of Solon (1999), finding 
that parental effects account for a small share of the overall sibling correlation irrespective of the trait or outcome considered.

An alternative approach for assessing the role of family characteristics in shaping siblings correlations is provided by Mazumder (2008) who estimates the correlation before and after conditioning sibling earnings on family attributes in a mixed model framework. When family attributes are limited to fathers' permanent incomes, this approach is equivalent to the decomposition of equation (3), the difference being that it does not assume stationarity of the distribution of permanent incomes between generations. Using this method on US data, Mazumder (2008) reports that approximately one third of the sibling correlation in long run incomes is accounted for by parental incomes. Applying this approach to Swedish data, Bjorklund et al. (2010) report a reduction of the sibling correlation of 0.032 (or 13 percent) after controlling for fathers' income among the explanatory variables of siblings long run incomes.

Understanding what factors determine the sibling correlation is the aim also in Page and Solon (2003a, 2003b). There the focus is not on parental incomes but rather on other shared influences, namely neighbours. They contrast sibling correlations in earnings with correlations in earnings between neighboring boys and girls, finding that family effects matter more than neighbour effects. Thus, similarly to the studies that consider the effects of parental incomes, they find that a large portion of the sibling correlation remains unexplained.

\subsection{Estimation biases}

Estimating intra-family income associations is complicated by measurement error issues. The works of Solon (1992) and Zimmerman (1992) represent seminal contributions in this respect. Both studies demonstrate that research preceding them substantially underestimated the IGE of incomes. This occurs because those studies use measures of parental incomes that are mixtures of long-term incomes and transitory income shocks, the latter being equivalent to classical measurement error. Both authors show that averaging point-in-time data on parental incomes over a limited number of time periods is sufficient to mitigate measurement error and to raise the income IGE for the US to substantially higher levels than previously thought, 0.4 versus 0.2. Mazumder (2005) further investigates the issue by considering the impact on the estimated IGE of averaging fathers' incomes on longer time windows than the four- or fiveyears used by Solon (1992) and Zimmerman (1992). When transitory shocks are not purely transitory but are characterized by serial correlation, the measurement error on permanent incomes becomes more severe and harder to integrate out, a point already acknowledged both 
by Solon (1992) and Zimmerman (1992). Indeed, simulations by Mazumder (2005) show that a moderate (0.5) degree of serial correlation in transitory incomes requires 30 years of data for measurement error to be integrated out almost entirely. Using data on sixteen-year income strings for fathers, Mazumder's preferred estimate of the IGE is 0.6.

Transitory shocks are not the only source of bias in estimating the IGE. Concurrent research on what has come to be known as 'life cycle bias' demonstrates that variation of long-term income over the life cycle can also impart a downward bias on the IGEs. This happens because fathers' and sons' incomes are sampled at different phases of the life cycle, typically too early for sons and too late for fathers, when current measures under- and overestimate (respectively) long-term ones. These issues where initially discussed by Jenkins (1987) in the context of intergenerational analyses, and their implications for estimating the IGE were empirically illustrated by Grawe (2006). Life cycle bias is an issue not only for intergenerational analyses, but in all those instances in which the researcher is interested in measures of lifetime earnings but only observes a limited part of the life cycle. Haider and Solon (2006) show that if there is individual heterogeneity in life cycle earnings growth, then the relationship between current and lifetime earnings varies over the life cycle, and the bias incurred by using annual in place of lifetime measures is minimized in the 30-40 age range. ${ }^{5}$ Anti-Nielsen et al. (2011) analyse intergenerational mobility in Norway using long strings of data on both fathers and sons. They show that taking averages of fathers' incomes over longer time windows than preceding studies increases the estimated elasticity. Increasing the starting age for fathers' income strings has the opposite effect. Transitory shocks and life cycle biases can explain these findings. In the context of intergenerational analyses, Nybom and Stuhler (2011) show how life cycle bias gives rise to non-classical measurement error. They show that current strategies for estimating the IGE are still prone to substantial bias, and conclude calling for an explicit allowance for heterogeneous life cycle growth across individuals in studies of intergenerational income associations.

The strategies that previous studies have suggested for coping with transitory shocks and life cycle biases conflict with each other. While transitory shocks are better dealt with using long strings of individual earnings, life cycle bias is minimized over a string of limited length, the ten years between ages 30 and $40 .{ }^{6}$ In this paper we follow a different strategy that allows us to resolve this tension. We use tools from the earnings dynamics literature to model

\footnotetext{
${ }^{5}$ Böhlmark and Lindquist (2006) obtain results for Sweden that are remarkably close to the ones of Haider and Solon (2006).

${ }^{6}$ See e.g. Björklund et al. (2009) for an application of this approach in the context of sibling studies.
} 
(rather than averaging out) the two sources of bias, namely serially correlated shocks and heterogeneous earnings growth. Our approach avoids informational losses and allows a characterization of life cycle effects in intra-family correlations of permanent earnings.

\subsection{Models of earnings dynamics}

There exists a well-established literature on modelling individual earnings dynamics; see the survey articles by Meghir and Pistaferri (2011) and Browning and Ejrnæs (2013). Papers in this tradition typically start from a permanent-transitory characterisation of the log earnings process (in deviation from some central tendency) and pay considerable attention to the dynamic properties of the two components. ${ }^{7}$ The permanent-transitory specification is well suited for the analysis of earnings correlations within the family since it allows isolating the measurement error caused by transitory shocks discussed above. Transitory earnings components are usually specified as low order ARMA processes. Two main approaches to the analysis of permanent earnings dynamics have been put forward in this literature. The first approach is based on the Random Growth (RG) or Heterogeneous Income Profile (HIP) model, see e.g. Lillard and Weiss (1979), Hause (1980), Baker (1997), Haider, (2001), Guvenen (2007) and Gladden and Taber (2009). The RG-HIP model assumes that individual earnings evolve over the life cycle according to an individual-specific earnings profile, which is linear in age or experience (we use age). Thus, the model allows for two sources of persistent individual earnings differences, namely time-invariant heterogeneity (individualspecific intercepts) and growth rate heterogeneity (individual-specific slopes). Linearity in earnings levels implies a quadratic age profile of earnings variances. ${ }^{8}$ By accounting for heterogeneous earnings growth across individuals, this parameterisation accommodates the recommendations of the life cycle bias literature that allowance has to be made for growth heterogeneity when studying earnings correlations across family members (Haider and Solon; 2006; Nybom and Stuhler, 2011). The RG-HIP model can be summarised as follows:

$$
y_{i t}=a_{i}+b_{i} A_{i t} ;\left(a_{i} b_{i}\right) \sim(0,0 ; \operatorname{var}(a), \operatorname{var}(b), \operatorname{cov}(a, b))
$$

\footnotetext{
${ }^{7}$ Most of these studies focus on the earnings process in isolation from other outcomes; exceptions are Abowd and Card (1989) who model the dynamics of earnings and working hours, and Altonji et al. (2013) who model the dynamics of earnings, hours, wage rates, unemployment and job tenure.

${ }^{8}$ Baker (1997) experiments with individual-specific quadratic profiles, concluding that they do not add much to the analysis compared with linear profiles.
} 
where $y_{i t}$ is $\log$ permanent earnings and $A_{i t}$ is age. This simple model can capture important features of individual earnings dynamics. Variances of intercepts and slopes of the profile correspond to different sources of earnings heterogeneity that have theoretical counterparts in human capital models, such as heterogeneous returns to schooling (intercepts) and heterogeneous returns to experience (slopes). A relevant parameter is the covariance between intercepts and slopes of the profile. Many studies have found the covariance to be negative. With $\operatorname{cov}(a, b)<0$, individuals starting-off with low pay will see their earnings grow faster than initially higher paid individuals, which may either reflect Mincerian cross-overs due to on-the-job training (Hause, 1980), or the willingness of those on fast tracks to accept low paid jobs at labor market entry. Whatever the causes, a negative covariance between intercepts and slopes implies that individual profiles converge at some point after labor market entry. Conventionally, the cross over point of converging profiles can be computed as the age at which permanent earnings variance is minimised (such variance should be zero if all profiles converged contemporaneously), i.e. $A^{*}=-\operatorname{cov}(a, b) / \operatorname{var}(b)$. The convergence of permanent earnings implies that within a birth cohort permanent inequality of earnings displays a u-shaped profile, and that intragenerational earnings mobility increases up to $A^{*}$, and then decreases.

The second approach is based on Random Walk (RW) specifications assuming that the permanent earnings component evolve through the arrival of infinitely lived shocks $(z)$ :

$$
y_{i t}=y_{i t-1}+z_{i t} ; y_{i t\left(A_{0}\right)} \sim\left(0, \operatorname{var}\left(y_{i t\left(A_{0}\right)}\right)\right) ; z_{i t} \sim(0, \operatorname{var}(z))
$$

where $A_{0}$ is the starting age and $t\left(A_{0}\right)$ is the corresponding time period, so that $y_{i t\left(A_{0}\right)}$ is the initial condition of the process. See among others MaCurdy (1982), Dickens (2000), Meghir and Pistaferri (2004) and Hyrisko (2012). This specification (also called Restricted Income Profile, RIP, because there is no heterogeneity in earnings profiles) translates into a linear evolution of earnings variance over the life cycle. One virtue of the RW-RIP model is that it fits well within models of life cycle optimization with rational expectations. As shown in Guvenen (2007), for the RG-HIP model to be used in a dynamic optimization framework one needs to specify the process of individual learning on the heterogeneous profile.

While most of these studies use one model or the other, there are also examples of eclectic approaches using mixtures of the two specifications, such as Baker and Solon (2003), and Moffitt and Gottschalk (2012). This is also the approach of our paper. 


\section{A model of earnings dynamics for fathers and sons}

We study earnings dynamics within the family. We do this using a model of multi-person earnings dynamics which provides a contribution to each of the three strands of literature reviewed in the previous section. We contribute to the earnings dynamics literature because ours is a model of the joint earnings process of three individuals linked by blood. We contribute to the literature on estimation biases because, by modelling both heterogeneous earnings growth and serially correlated transitory shocks, we resolve the tension faced by previous studies when choosing the length of the income strings analysed. Finally, we contribute to the sibling literature by providing a direct decomposition of the sibling correlation into intergenerational and residual sibling components that accounts for heterogeneity of intergenerational transmission in the population.

We focus on men and distinguish three types of family members, fathers $(F)$, first-born sons (S1) and second-born sons (S2), indexed by $h .{ }^{9}$ For each family member, we consider individual log-earnings in deviation $(w)$ from the mean, where the mean varies by year, birth cohort and type of family member. ${ }^{10}$ Log-earnings deviations from the mean consist of a permanent (long-term) component $(y)$ and an orthogonal transitory (mean-reverting) shock (v), orthogonality holding by the definition of permanent and transitory components of earnings. Total earnings are written as the sum of the two orthogonal components:

$$
w_{i j t}^{h}=y_{i j t}^{h}+v_{i j t}^{h} ; E\left(y_{i j t}^{h}, v_{i j t}^{h}\right)=0
$$

where the indices $i, j$, and $t$ stand for individual, family and time period.

\subsection{Permanent earnings}

We model permanent earnings by combining insights from literatures on sibling correlations and earnings dynamics. We innovate the model of equation (1) in two key directions. First, we distinguish the intergenerational effect and the residual sibling effect within the overall sibling component. In this way, for the first time we provide a direct assessment of the role of

\footnotetext{
${ }^{9}$ Only $4 \%$ of families are observed with more than two sons, see Section 4.

${ }^{10}$ Considering earnings in deviation from yearly means by birth cohort is a flexible way of removing average age effects that may confound the estimation of individual life-cycle profiles, see Baker and Solon (2003). Here we apply the "de-meaning" procedure distinguishing the different types of family members and adjusting for within-cohort age differences (we work with three-year birth cohorts) through quadratic trends, which we achieve by taking residuals from cohort/member-specific regressions of log earnings on calendar year dummies and quadratic age trends.
} 
intergenerational transmission within the omnibus sibling earnings correlation while allowing for its heterogeneity in the population. It is worth stressing that in this way we identify the transmission of earnings from fathers to sons, and we are silent about other channels of intergenerational transmission working independently of father's earnings. In this sense our decomposition provides a lower bound to the intergenerational component of sibling correlations.

Second, we introduce life cycle effects. We specify earnings components shared across family members using the RG-HIP parameterisation. This is motivated by the need to allow for heterogeneous earnings profiles in order to avoid life cycle biases. Also, in the next Section we will provide evidence that empirical sibling correlations are u-shaped in age, a pattern that can be captured by a RG-HIP model and not a RW-RIP. Note that in this multiperson context the RG-HIP model can be more easily justified from the informational viewpoint than in models of single-person earnings dynamics, i.e. sons may already know the parameters of their earnings process at labor market entry by observing the earnings profiles of their fathers or of other members of their communities. We maintain the RW-RIP specification for the idiosyncratic component of permanent earnings. ${ }^{11}$ Sons' earnings are written as:

$$
\begin{gathered}
y_{i j t}^{h}=\left(\left(\mu_{j}^{I}+\mu_{j}^{R}\right)+\left(\gamma_{j}^{I}+\gamma_{j}^{R}\right) A_{i t}+\omega_{i j t}^{h}\right) \pi_{t}, \quad h=S 1, S 2 \\
\omega_{i j t}^{h}=\omega_{i j t-1}^{h}+\phi_{i j t}^{h} .
\end{gathered}
$$

There is a linear earnings profile in age, and intercepts and slopes of the RG-HIP model depend upon sibling-specific effects. Sibling effects have an intergenerational component indexed by $I$ - and a residual sibling component-indexed by $R$. They represent permanent traits of earnings shared by brothers, coming either from their father's earnings, or from other factors independent of father's earnings. The idiosyncratic component $\left(\omega_{i j t}^{h}\right)$ is a RW-RIP process capturing persistent individual-specific deviations from the sibling effect. In order to avoid life cycle variation being confounded by secular trends of earnings inequality, following Moffitt and Gottschalk (1995) we also introduce time effects through periodspecific loading factors $\pi_{t}$.

Identification of intergenerational effects within the overall sibling component requires father's earnings to be modelled jointly with sons' earnings. We therefore specify a model for

\footnotetext{
${ }^{11}$ There are additional empirical considerations supporting our choice of specification, see footnote 18.
} 
father's earnings similar to that of sons, with the exception of the residual sibling effects that are shared by siblings only and do not feature in father's earnings; residual siblings effects are therefore empirically identified by the availability of both sibling and intergenerational earnings correlations. The model for father's earnings is:

$$
y_{i j t}^{F}=\left(\mu_{j}^{I}+\gamma_{j}^{I} A_{i t}+\omega_{i j t}^{F}\right) \pi_{t} .
$$

Each individual- or family-specific parameter of the model is drawn from a zero mean unspecified distribution. RG-HIP intercepts and slopes are correlated within each dimension of family-specific heterogeneity (intergenerational and residual siblings) and are assumed independent between dimensions. ${ }^{12}$ We allow RW parameters to be drawn from memberspecific distributions. In sum, the distribution of permanent earnings is specified as follows:

$$
\begin{gathered}
\left(\omega_{i j t\left(A_{0}\right)}^{h}, \phi_{i j t}^{h}\right) \sim\left(0,0 ; \sigma_{\omega 0 h}^{2}, \sigma_{\phi h}^{2}\right) \\
\left(\mu_{j}^{I}, \gamma_{j}^{I}\right) \sim\left(0,0 ; \sigma_{\mu I}^{2}, \sigma_{\gamma I}^{2}, \sigma_{\mu \gamma I}\right) \\
\left(\mu_{j}^{R}, \gamma_{j}^{R}\right) \sim\left(0,0 ; \sigma_{\mu R}^{2}, \sigma_{\gamma R}^{2}, \sigma_{\mu \gamma R}\right) .
\end{gathered}
$$

Having specified a model with age related growth and idiosyncratic, intergenerational and residual sibling sources of heterogeneity in permanent earnings, we can decompose the overall sibling correlation of permanent earnings over the life cycle $\left(\rho^{S}\right)$ into its intergenerational $\left(\rho^{I}\right)$ and residual sibling $\left(\rho^{R}\right)$ components:

$$
\rho^{S}(A)=\rho^{I}(A)+\rho^{R}(A) .
$$

This decomposition is the counterpart of the ones used in previous studies, with the difference that it incorporates heterogeneity of intergenerational transmission in the population. Another notable difference with previous studies is the allowance for age effects in the sibling correlation and its components. Details on the decomposition are provided in the Appendix.

\subsection{Transitory earnings}

\footnotetext{
${ }^{12}$ We assess this last assumption in Section 6 when we consider estimates from nested models.
} 
Previous literature on individual earnings dynamics has used low order ARMA processes to model transitory shocks. Intergenerational or sibling studies, on the other hand, have been mostly resorting to multi-period averaging to integrate out earnings shocks and reduce measurement error biases, choosing the number of periods on the basis of the assumed degree of serial correlation. One exception is the paper by Björklund et al. (2009) who explicitly model correlated shocks as stationary AR(1) processes concentrating on the $30-40$ age range, assuming shocks uncorrelated across siblings.

In this paper we specify transitory earnings as member-specific AR(1) processes. We allow for age-related heteroskedasticity in the innovations of the process using an exponential spline. Baker and Solon (2003) demonstrated the existence of significant u-shaped age variation in the dispersion of transitory shocks, and it is important to allow for it in our model so as to avoid this variation being incorrectly imputed to permanent earnings. We also allow for contemporaneous correlation of transitory shocks across family members. Our transitory earnings model is as follows:

$$
\begin{gathered}
v_{i j t}^{h}=\tau_{t} u_{i j t}=\left(\rho_{h} u_{i j t-1}+\varepsilon_{i j t}\right) \tau_{t}, \quad \varepsilon_{i j t} \sim\left(0, \sigma_{\varepsilon h A}^{2}\right), \sigma_{\varepsilon h A}^{2}=\sigma_{\varepsilon h}^{2} \exp \left(g_{h}\left(A_{i t}\right)\right) \\
u_{i j s} \sim\left(0, \lambda_{c}^{d\left(s=t_{0}\right)} \sigma_{s h}^{2}\right), \quad s=\max \left(t_{0}, c+A_{0}\right), \\
E\left(\varepsilon_{i j t} \varepsilon_{k j t}\right)=\sigma_{h l}, h, l=F, S 1, S 2, \quad h \neq l .
\end{gathered}
$$

where $c=c(i)$ denotes the birth cohort of person $i$ and $t_{0}$ the first year of available data, so that $s=s(c)$ is the first year in which individuals belonging to a given cohort are observed. We allow for non-stationarity by modelling the initial condition of the transitory process and introduce cohort effects in initial conditions $\left(\lambda_{c}\right)$ for cohorts starting their life cycle prior to the initial year of observation, $d\left(\right.$ ) being an indicator function. $\tau_{t}$ is a period specific loading factor and $g_{h}($ ) a member-specific linear spline. Each family member draws transitory shocks from a member-specific distribution, and shocks are (contemporaneously) correlated across members. Our model, therefore, includes parameters capturing intergenerational and sibling correlations of transitory earnings shocks, which have both been assumed away in the previous literature. Note that if transitory shocks are positively correlated across persons, then the between-member correlation of current earnings provides an upward biased estimate of correlations in permanent earnings.

\subsection{Estimation}


The model fully specifies the inter-temporal distribution of permanent and transitory earnings for each family member and between members. The second moments of this distribution are a non-linear function of a parameter vector $\theta$ that contains RW-RIP, RG-HIP and AR(1) coefficients, plus period factor loadings on permanent and transitory earnings. Details on moment restrictions are provided in the Appendix. We estimate $\theta$ by Minimum Distance (see Chamberlain, 1984; Haider, 2001). ${ }^{13}$ In order to identify age effects separately from time effects, we derive birth-cohort specific empirical earnings moments and stack them in a single moment vector for estimation.

\section{Sample selection and raw correlations of earnings within the family}

We use data from administrative registers of the Danish population. The civil registration system was established in 1968 and everyone resident in Denmark then and since has been registered with a unique personal identification number which has subsequently been used in all national registers enabling accurate linkage. Links from children to legal parents originate from municipal and parish records and are complete for births from 1955 onwards (Pedersen, et al. 2006). We have complete legal parentage for men and women born from 1935 onwards. Children changing legal parentage through adoption before age 17 are dropped from the sample. We sample fathers born from 1935 and consider only sons born to first father-mother pair, conditional on father's age at first birth being 18 or older. First-sons and second-sons are included, and subsequent sons (4 per cent) are ignored. If the first son or second son has a twin brother, the twin pair is dropped. Non-twin brothers born less than 1 year apart are also dropped. Second sons are dropped if they are born more than 15 years after the first. Finally we derive a sample of father/first-son/second-son triplets and father/first-son couples. ${ }^{14}$ Women play no role in the analysis after determining full brotherhood. ${ }^{15} \mathrm{We}$ select fathers born 1935-1964, first sons born 1959-1982 and second sons born 1962-1982. This is because of completeness of registered parentage and the small number of first sons observed born before 1959. The distribution of birth cohorts sampled is shown in the left panel of

\footnotetext{
${ }^{13}$ We use Equally Weighted Minimum Distance (EWMD) and a robust variance estimator $\operatorname{Var}(\theta)=\left(G^{\prime} G\right)^{-}$ ${ }^{1} G^{\prime} V G\left(G^{\prime} G\right)^{-1}$, where $V$ is the fourth moments matrix and $G$ is the gradient matrix evaluated at the solution of the minimisation problem.

${ }^{14}$ By analogy with the sibling correlations literature that uses samples including singletons, we also consider families consisting of father/first-son couples only

${ }^{15}$ Son birth order is determined irrespective of the presence of daughters: for example, we do not make any distinction for whether there is a daughter born in-between the two sons, before or after. We study men and do not consider mother/son, father/daughter or brother/sister associations. We assess results robustness to the presence of sisters in Section 8.
} 
figure 1. Birth cohorts of fathers and sons overlap 1959-64 but we drop grandsons, i.e. we do not include fathers who were themselves observed as sons.

We model annual pre-tax labor earnings which are obtained from income tax returns. Each January employers report earnings for the previous year for each employee to the tax authorities and to the employees themselves for verification. We use the sum of earnings from all employments during the year for the period 1980-2011 over which it is available in the Statistics Denmark Income Statistics Register (Baadsgaard and Quitzau, 2011). In order to model life cycle dynamics we require observation of individual earnings strings over time. We focus on prime age men and conventionally set the start of the life cycle $\left(A_{0}\right)$ at age 25 and its final point at age 60. Consequently we observe fathers throughout this range 25-60, first sons 25-51 and second sons 25-48. The distribution of ages of earnings observations is shown in the right panel of figure 1. Most observations are for fathers' earnings 7,103,657, with 4,557,218 for first son and 1,157,438 for second son. Mean ages for earnings observations are 45.8, 33.2 and 32.5 respectively.

We group individuals into 3-year birth cohorts, imputing the central age to each cohort group, and hereafter refer to cohort groups by this central age. Imposing a cohort structure on the data is fundamental for separating life cycle effects from calendar time, and this is the established practice of earnings dynamics studies, see e.g. Baker and Solon (2003).

The combination of sample selection criteria generates a data-set which is described in the left panel of Table 1 for selected years in terms of first and second moments of the annual earnings distribution and average age. On this sample we apply two additional selections which are typical in the earnings dynamics literature. First, we exclude outliers by trimming half percentile on each tail of the earnings distribution of each year; since the analysis will exploit empirical earnings moments separately by family members, we perform the trimming within the distribution of each type of member. ${ }^{16}$ Secondly, in order to ease identification of earnings profiles we require the availability of at least five consecutive individual data points, a selection rule that is intermediate between the one used by Baker and Solon (2003), i.e. continuous earnings strings for each individual within a cohort, and the approach of Haider (2001), who allows individuals to move in and out of the sample only requiring two positive but not necessarily consecutive valid observations on earnings. Other than this, we use all valid observations on earnings and exclude zero-earnings observations. The exclusion of zeroearnings observations is common with most of the earnings dynamics literature assuming that

\footnotetext{
${ }^{16}$ Bingley et al (2013) show that estimates of earnings components models are robust to alternative trimming rules.
} 
earnings are missing at random, and is also applied in the sibling correlation literature by Björklund et al (2009). The final estimating sample resulting from the last set of selections is described in the right panel of Table 1. Trimming outliers and imposing partially continuous income strings has an impact on sample size. There is also an impact on earnings dispersion, while average earnings are not much affected. In total, our sample consists of 741,038 persons belonging to 326,341 families of which 88,356 are triplets. Individuals are observed for 17.3 years on average (fathers 21.7, first sons 14.0 and second sons 13.1), giving 12,818,313 earnings observations.

We begin describing patterns of earnings associations within the family in Figure 2, where we plot intergenerational and sibling correlations of raw log earnings. Earnings are adjusted for time and age effects by regressing for each birth cohort the log of real annual earnings on time dummies and a quadratic in age. Earnings moments in this and the following sections are derived using the residuals of these regressions. We discard empirical second moments that are based on fewer than 100 cases throughout the analysis. Intergenerational correlations are derived averaging father-son correlations for both sons by sons' ages. There are two plots in each panel of the figure; the plot labelled "Same age" is derived computing the average of correlations conditioning on the age of fathers being equal to the age of sons, while the plot labelled "Fixed age" conditions on the age of fathers being equal to 40.

Intergenerational correlations are low, in line with results from previous research that places Denmark at the bottom of international rankings of family earnings associations, see e.g. Björklund and Jännti (2009). There is a relevant difference in earnings associations if one contrasts same-age figures with fixed-age ones; while the contemporaneous correlation fluctuates in the range between 0.05 and 0.1 with no clear pattern when the son ages from 25 to 48 , the associations with a father aged 40 are very low, actually negative, at young ages, and converge to contemporaneous figures when the son approaches the age of 30 . This is a symptom of life cycle bias: estimating intergenerational correlations between fathers and sons observed at different stages of the life cycle provides an underestimate of the correlation resulting at comparable ages. The fact that the data allows us to observe the bias suggests that the information derived from the population register provides an adequate basis for controlling the bias.

We repeat the exercise with sibling earnings raw correlations in the left panel of Figure 2. The "Fixed age" plot refers to an older brother aged 30 and shows, again, upward trends at early ages, followed by a stabilisation around "Same age" figures thereafter. Remarkably, the "Same age" plot displays a u-shaped age profile, which is consistent with a RG-HIP model of 
earnings dynamics with Mincerian cross-overs, in which siblings share both fixed and time varying components of earnings and the two are negatively correlated. The large contemporaneous associations at early life cycle stages may also reflect correlation of transitory shocks. It is well known that earnings instability is large for young cohorts (see e.g. Baker and Solon, 2003) and it is plausible that siblings are subject to common shocks, for example because of similar local economic conditions at labour market entry.

As a way to assess if the relatively large sibling correlation at young ages is driven by permanent earnings differences or transitory fluctuations, we computed sibling correlations for brothers born at least five or eight years apart (not shown). The larger the age difference, the less likely it is that brothers share transitory shocks at labor market entry, so that these samples are less likely to be influenced by transitory fluctuations compared with the samples underlying Figure 2. A declining pattern of the sibling correlation between the mid-20s and the mid-30s and the subsequent stabilization persist even after excluding closely spaced brothers that most likely share transitory earnings fluctuation. This suggests that the source of the $\mathrm{u}$-shape evolution of sibling correlations is in the permanent earnings component, pointing towards the appropriateness of a RG-HIP specification. It is worth emphasising that our model also features age-dependent transitory shocks and is thus capable of distinguishing age effects within each earnings component. ${ }^{17}$

\section{Results}

We begin the discussion of results by focusing on estimates of parameters for the permanent and transitory component, which are reported in Tables 2 and 3; period factor loadings for both components are reported in Table 4. Parameters are estimated by imposing the moment restrictions implied by the model on empirical second moments of earnings, after excluding moments based on fewer than 100 individuals. We base the analysis on 5394 within-person moments (of which 3624 refer to fathers, 1344 to first sons and 966 to second sons), 17,620 father/first-son moments, 12,702 father/second-son moments and 8046 brother/brother moments. There are 44,302 empirical moments in total.

\footnotetext{
${ }^{17}$ An additional reason for the declining sibling correlation between age 25 and 30 could be selection into the labour market: at age 25 school-to-work transition might still be incomplete for a non-random sample of the population and the sources of non-randomness might be correlated between siblings. In our estimating sample 8 per cent of brothers enter the labour market after the age of 25. To assess whether life-cycle patterns of sibling correlations are an artefact of selection into the labour market, we re-estimated raw correlations limiting the sample to siblings whose earnings profiles are observed since the age of 25 , and found that the level and lifecycle evolution of the sibling correlation are virtually identical to the ones depicted in Figure 2.
} 


\subsection{Permanent earnings}

Results for the RG-HIP/RW-RIP model are reported in Table 2. The table distinguishes parameters of the distribution of shared components (intergenerational and residual sibling) from those of the (member-specific) idiosyncratic component one.

There are differences in idiosyncratic parameters between fathers and sons, demonstrating the importance of allowing for type-specific distribution of idiosyncratic effects. These differences are especially evident in the variance of RW-RIP innovations, which is the parameter driving the evolution over time of idiosyncratic earnings dispersion. Results indicate that shocks are more dispersed for sons compared with fathers, which might itself reflect life cycle variation in the variance of shocks, as fathers in our sample are observed on average at later stages of the careers than sons. Substituting the member-specific RW-RIP with a member-specific RG-HIP process confirmed that sons earnings profiles are more dispersed than fathers, while leaving our substantive results on the sibling correlation (presented later in this section) unaffected. We therefore maintain the RW-RIP specification of the idiosyncratic component because it increases the generality of the model in that the resulting specification of permanent earnings brings together elements of both the RW-RIP and RG-HIP models. ${ }^{18}$

Heterogeneity in sibling effects -intergenerational and residual sibling- is substantial. Considering initial earnings, for sons a bit less than half of the variance comes from sibling effects. Heterogeneity of intergenerational effects is predominant within the sibling-specific distribution of initial earnings. Sibling effects are also evident in the distribution of earnings growth rates, but with different patterns. Namely, the residual sibling component and the intergenerational one appear to contribute equally to heterogeneity in earnings growth, the corresponding parameter estimate being of the same size. Looking at the covariance between RG-HIP intercepts and slopes, Table 2 shows that both the intergenerational and residual sibling components are negative and statistically significant. The negative signs indicates the presence of Mincerian cross-overs in the distribution of permanent earnings, with a cross-over age $A^{*}$ located at 32 and 34 years for the intergenerational and residual sibling components, respectively. The faster compression of the residual sibling component reflects the larger (in absolute value) estimate of the intercept-slope covariance. Insofar as Mincerian cross-overs emerge from heterogeneous investments in human capital, our results suggests that the

\footnotetext{
${ }^{18}$ In background analyses we experimented with a RW-RIP specification also for the shared components, obtaining negative estimated variances of the shocks. This result might be a consequence of the u-shaped pattern of empirical sibling correlations illustrated in Figure 2, which cannot be captured by a RW-RIP specification.
} 
determinants of these investments are associated with factors that siblings share, either associated with paternal earnings, or orthogonal to them. Mincerian cross-overs imply that the predicted variance of permanent earnings explained by shared components will first decrease and then fan out over the life cycle. It is worth stressing that we obtain this result in a model that controls for age effects in transitory earnings, ruling out "omitted variable bias" induced by higher instability at young ages.

\subsection{Sibling correlation in permanent earnings and its components}

Figure 3 reports the life cycle evolution of the sibling correlation as well as its decomposition into intergenerational and residual sibling effects. This decomposition is obtained bu substituting estimated parameters in equation (10). ${ }^{19}$ It represents the counterpart of decompositions from previous studies on the basis of equation (3). The overall sibling correlation is about 0.5 at the start of the life cycle and depends mainly on intergenerational effects. The initial value is about twice that reported for Denmark by previous studies (Björklund et al., 2002, report a sibling correlation in annual earnings of 0.23). As individuals age, overall sibling correlation diminishes, and becomes smaller than 0.3 between the ages of 30 and 40, the age range for many previous correlation measures. The reason for the rapid drop in sibling correlations is the shrinking of the overall intra-generational earnings distribution (Mincerian cross-overs) which is driven by sibling effects. After the cross-over point, the intragenerational earnings distribution starts opening up again as an effect of heterogeneous earnings growth, so that the overall sibling correlation increases. Note also that the cross-over point of earnings profiles is located in the mid-30s, and that the 30-40 age range will contain many siblings pairs with one brother either side of the cross-over point. Hence, while the earnings distribution of the older brother will be opening up, the distribution for the younger brother will still be compressing, which further contributes to the reduction of sibling correlations in this age range. This effect will cease after the younger brother also passes the cross-over point, and the sibling correlation will start increasing. The average sibling correlation between age 25 and 48 is 0.228 ; it is 0.237 in the $25-42$ age range used in previous studies for Denmark.

Besides the significant life cycle variation, another remarkable fact displayed in Figure 3 is that intergenerational correlations explain between 58 and 90 per cent of the total sibling correlation. On the other hand, the residual sibling component is sizeable and significant only

\footnotetext{
${ }^{19}$ See the Appendix for details. The graph is generated using idiosyncratic parameters of young brothers, but we obtained almost identical patterns using the average of brothers' parameters.
} 
at the start of the life cycle, but becomes rapidly negligible, and it is not significantly different from zero at age 35; it increases again towards the late 40s and reaches the level of about 0.07 by age 48 . Also, the intergenerational component seems to be less sensitive to life cycle variation compared with the residual sibling component. Figure 3 suggests that intergenerational effects account for a larger share of the overall sibling correlations than previously thought. The average share of total correlation accounted for by the intergenerational component is 80 per cent. Our result is in line with those sibling studies concluding that environmental factors external to the family play only a small role in generating income correlation across brothers (see e.g. Page and Solon, 2003b).

\subsection{Transitory earnings}

Results for the member-specific AR(1) model for the transitory part of the earnings process are reported in Table $3 .{ }^{20}$ The characteristics of the process governing transitory shocks are similar for the three family members. The estimate of the parameter $\sigma_{\varepsilon h}^{2}$ (baseline shock volatility at age 25) is larger for fathers than sons, but the difference is not statistically significant. Patterns of age-related heteroskedastic shocks volatility are in line with previous findings reported by Baker and Solon (2003), i.e. decreasing at young ages and increasing at older ages, with the latter effect being visible only for fathers, who are the only family members observed after age 51. Also, autoregressive coefficient estimates are of moderate size and tend to be rather stable across family members. On the other hand, the estimated variance of the $\operatorname{AR}(1)$ initial conditions $\left(\sigma_{s h}^{2}\right)$ is larger for sons, a consequence of the fact that for sons we do not allow for cohort-specific shifters of the initial conditions on left-censored cohorts, as all birth cohorts of sons start their observation windows at age 25 . Therefore, for sons the variance of initial conditions also reflects heterogeneity between cohorts.

Transitory shocks are positively correlated across family members, in particular across brothers. Moreover there is more correlation between fathers and younger brothers than between fathers and older brothers, but the difference is insignificant. For brothers, the correlation coefficient at age 26 implied by the estimates is 0.028 , i.e. about one twentieth of the sibling correlation of permanent earnings at the same age. While quantitatively small, the existence of a significant correlation questions the ubiquitous assumption in sibling studies that transitory shocks are uncorrelated across siblings.

\footnotetext{
${ }^{20}$ As illustrated in Section 3, this model allows for age-related heteroskedasticity in transitory shocks through an exponential spline. We also experimented with the quartic specification of Baker and Solon (2003) finding results very similar to those discussed here.
} 


\section{Nested models}

One useful feature of our model is that it nests the models used by previous studies, namely intergenerational-only models, siblings-only models, and models without life cycle effects. To what extent do nested models that exploit only one dimension of family earnings associations or ignore earnings growth miss a part of the picture? We now address this question by imposing restrictions on our model.

We present results for permanent earnings from nested models in Table 5. We start in Column (1) with a model that excludes life-cycle variation in permanent and transitory earnings. This is essentially the model of equation (1), but with the sibling component $f_{j}$ splitting up into intergenerational and residual siblings components. ${ }^{21}$ This is an important benchmark of our main results since this is the workhorse model of many previous sibling studies (e.g. Björklund et al., 2009) and the one underlying the decomposition of sibling correlations of equation (3). Estimated parameters of this model result in a sibling correlation of 0.26 , which is larger than the average of the age-specific sibling correlation correlations of Figure 3 (0.228). The model attributes 60 per cent of sibling correlation to the intergenerational component, whereas we saw this component accounting for a larger share of total correlation in the more comprehensive model with life cycle variation. Thus, ignoring age effects has an impact on the average sibling correlation and induces a bias in the estimation of its components, in particular by underestimating the effect of the less agesensitive component, i.e. the intergenerational one. It is worth noting that the decomposition formula used in previous studies was derived under the assumption of life cycle constancy of earnings, and that those studies unanimously concluded that residual sibling effects dominate intergenerational ones. However, comparing the share of 60 per cent implied by our restricted model estimates with the 6 per cent reported by Björklund and Jännti (2009), suggests that imposing constancy alone is not enough to replicate the finding from previous studies that intergenerational effects are negligible. Also the other hypotheses underlying the approaches of previous research may play a role, a point that we discuss further in the next section.

We report parameter estimates of permanent earnings from models that allow only for intergenerational effects in Column (2) of Table 5. The intergenerational model is obtained from the full model constraining to zero all parameters referring to the residual sibling component. The full model has been estimated under the assumption of no correlation between intergenerational and residual sibling effects. Estimation of the intergenerational-

\footnotetext{
${ }^{21}$ The other difference with equation (1) is the inclusion of time shifters $\pi_{t}$ and $\tau_{t}$ in our model.
} 
only nested model is informative about such a correlation. For example, if intergenerational and residual sibling effects are positively correlated, then omission of the latter should result in inflation of the former in the nested model. Parameter estimates in Column (2) of Table 5 are very close to their counterparts in Table 2, in particular those concerning intergenerational components of the model. In order to fully appreciate the impact of omitting residual sibling effects on the estimation of the intergenerational part of the sibling correlation, we plot predictions from the nested and full models in the left panel of Figure 4. Indeed, the nested model over-predicts the intergenerational correlation with respect to the full model. The difference between the two series is sizeable (about 0.1) and statistically significant at the start of the life cycle. The difference shrinks as individuals age, and becomes insignificant by age 30 .

To what extent do sibling-only models that have been used by previous research as a way to capture all factors shared by siblings, including intergenerational ones, replicate the overall sibling influence that we found in the previous section? Results on the siblings-only model are in Column (3) of Table 5. The model is estimated using sons' moments only, and constraining intergenerational parameters to be equal to zero. Predictions from this model are contrasted with those of the full model in the right panel of Figure 4, where it is apparent that there is no substantive difference between the two models. If anything, the sibling-only model -estimated only on the $27 \%$ of families with two sons-generates less precise prediction.

\section{Introducing heterogeneous IGE in the decompositions of previous studies}

Our results point towards a predominant role of fathers' earnings in explaining the sibling correlation, which contrasts with the findings of previous studies that fathers' incomes account for only a limited fraction of the sibling correlation. In the previous section we saw that excluding life cycle effects from our model explains some of the discrepancy, although it does not fully eliminate it. The aim of this section is to understand whether the difference in results are specific to our data or are due to the different assumptions underlying our model, especially that we allow intergenerational transmission to be heterogeneous across families. In order to do this we replicate the approaches of previous studies on our data and then we introduce IGE heterogeneity into those approaches.

We start with the decomposition of equation (3). The ingredients for the calibration are the sibling correlation of permanent earnings and the IGE. We define permanent earnings as the individual average of (residualized) annual earnings, in deviations from generational means. Following Mazumder (2008), we estimate the variance components using a mixed 
model and a Restricted Maximum Likelihood (REML) estimator, while we estimate the IGE using the canonical intergenerational regression of sons' earnings on fathers' earnings. Results are reported in the first panel of Table 7. We estimate the sibling correlation to be about 0.19 and the IGE to be $0.075 .^{22}$ These estimates imply that the share of the sibling correlation that is associated with fathers' earnings is 3 per cent. The second panel of Table 7 reports results from the sequential conditioning approach of Mazumder (2008) and Björklund et al. (2010). Again, the share of the correlation that can be ascribed to fathers' earnings is 3 per cent.

Applying the approaches of previous studies on our data yields a share of sibling correlation explained by fathers' earnings that is even lower than the ones of previous studies, which rules out data differences as the driver for differences in results. It must therefore be the set of assumption behind the approaches that makes the difference. One key assumption that we relax is that the IGE is constant across families. To assess the role played by this assumption, we exploit one useful feature of the above mixed model, namely the possibility of modelling the family component as a function of paternal incomes, by means of a random coefficient specification. Using the same model underlying the decomposition of equation (3) we further allow for heterogeneous IGE of permanent earnings. This is closer in spirit to our multi-person model of earnings because it looks directly at the heterogeneous impact of fathers' earnings on the variance components of sons' earnings, rather than performing comparisons of sibling correlations before and after conditioning on average effects. Using the notation of equation (1), the mixed model with random coefficient specification is:

$$
y_{i j}=a_{i j}+f_{j} ; f_{j}=\eta_{j} y_{j}^{F}+\bar{\eta} y_{j}^{F}+\xi_{j} ; \eta_{j} \sim(0, \operatorname{var}(\eta)), \xi_{j} \sim(0, \operatorname{var}(\xi)) .
$$

The model for the sibling-specific component $f_{j}$ has three terms. The second and third terms on the right hand side are the ones yielding the decomposition formula of equation (3), $\bar{\eta}$ being the (population average) IGE, $y_{j}^{F}$ is father's permanent earnings and $\xi_{j}$ is the residual sibling effect. The first term on the right hand side introduces heterogeneity of intergenerational transmission across families, where $\eta_{j}$ is the family-specific deviation from

\footnotetext{
${ }^{22}$ Using the same data source as us, Bonke et al. (2009) report a set of IGE estimates for Denmark showing their sensitivity to sample selections, in particular the age range when siblings are observed. They report an IGE of 0.07 for siblings taken in the same age range as in our sample, 25-51. The figure reported by Björklund and Jännti (2009; IGE=0.12) is cited from Bonke et al. (2009), who obtain it using siblings data in the 30-40 age range. Using data in that same range we obtain an IGE of 0.119 . Finding that the IGE declines with the length of the window of observation of sons earnings is consistent with our results that intergenerational transmission matters more for initial earnings than it does for earnings growth.
} 
$\bar{\eta}$, assumed independent of $y_{j}^{F}$. Abstracting from life-cycle effects, this specification is similar to our main model, with the difference that in equations (7) and (8) we make a distinction between components of father's permanent earnings that are passed intergenerationally and those that are purely idiosyncratic, whereas in equation (11) both are subsumed in the term $y_{j}^{F}$. Because permanent earnings are in deviations from generational means, all the random variables in (11) have expectation equal to zero, so that the sibling correlation decomposes as:

$$
r^{S}=\frac{\left(\operatorname{var}(\eta)+\bar{\eta}^{2}\right) * \operatorname{var}\left(y^{F}\right)}{\operatorname{var}(a)+\operatorname{var}(f)}+\frac{\operatorname{var}(\xi)}{\operatorname{var}(a)+\operatorname{var}(f)}
$$

with the first term on the right hand side capturing the component of the sibling correlation that is due to paternal earnings, while the second captures the residual component of the sibling correlation. The specification of $f_{j}$ in (11) is similar to the starting point in the derivation of the calibration formula of equation (3), but with a key difference, i.e. here we allow for the IGE to be family-specific. Indeed, by following Solon (1999) in assuming stationary distribution of permanent earnings across generation $\left(\operatorname{var}\left(y_{j}^{F}\right)=\operatorname{var}(a)+\right.$ $\operatorname{var}(f))$, equation (12) becomes:

$$
r^{S}=\operatorname{var}(I G E)+I G E^{2}+\text { residual sibling correlation }
$$

i.e. the counterpart of Solon (1999)'s decomposition in the case of heterogeneous IGE. It is clear from the decomposition formula (13) that allowing for heterogeneous IGE adds a positive component to the computation of intergenerational effects within the sibling correlation.

We report results obtained from the mixed model with heterogeneous IGE in the third panel of Table 7. If we assume stationarity of the earnings distribution across generations (decomposition formula (13)) we obtain that the share of sibling correlation that is accounted for by paternal earnings is 20 per cent. If instead we do not make the stationarity assumption (decomposition formula (12)), that share rises to about 26 per cent. Thus, even within the same modelling approach of previous studies, allowing for heterogeneous rather than homogenous IGEs increases the share of sibling correlation that is due to fathers' incomes by between six to almost nine times. 


\section{The impacts of family structure and differential intergenerational transmission}

In this section we provide answers to two questions. First, how sensitive are our results to the presence of additional siblings other than the first two sons? And, second, does intergenerational transmission differ between brothers?

Considering that only $4 \%$ of families are observed with more than two sons, we investigate the impact of family structure by focussing on daughters and divide families into two groups, those where there are no daughters and those in which there is at least one daughter. Results from this exercise are in Columns (1) and (2) of Table 6, which show that parameter estimates are relatively stable across sub-samples. The decomposition of sibling correlations for the two sub-samples is provided in Figure 5. For the sub-sample of families with at least one daughter (right panel), the decomposition resembles quite closely the one for the joint sample in Figure 3; estimates seem to be somewhat less precise for the sub-sample of families with daughters, a likely effect of reduced sample size. Families without daughters (left panel) are characterised by stronger intergenerational persistence and a reduced role for residual sibling effects whose point estimate approaches zero in the mid-30s. Again, estimates are less precisethan those for the pooled sample.

Differential treatment of siblings by parents is a topic that has attracted attention in the sibling literature, in particular because it may weaken the ability of sibling correlations to capture family effects (see e.g. Björklund and Jännti, 2009). The usual reference in this context are birth order studies showing that first born children exhibit better outcomes compared with later born siblings, a fact typically interpreted as parents investing more in first born children (Black et al., 2005). Björklund and Jännti (2012) show that residualization of earnings on birth order via mixed models has little impact on estimated sibling correlations. Whether the intergenerational transmission of outcomes (rather than outcome levels per se) varies with birth order is a different and related question which has received only little attention (Behrman and Taubman, 1986, Behrman, et.al, 1994, Hotz and Pantano, 2011), and we address this now for earnings.

Our analytical set-up allows for differential intergenerational transmission because we observe intergenerational earnings moments for each of the two sons; therefore we can specify intergenerational parameters to be different for the two sons. We do this by allowing intergenerational components to enter into younger sons' model through specific factor loadings $\delta_{\mu}$ and $\delta_{\gamma}$ : 


$$
y_{i j t}^{S 2}=\left(\left(\delta_{\mu} \mu_{j}^{I}+\mu_{j}^{R}\right)+\left(\delta_{\gamma} \gamma_{j}^{I}+\gamma_{j}^{R}\right) A_{i t}+\omega_{i j t}^{S 2}\right) \pi_{t} .
$$

The model is estimated on the sample that includes complete (three-member) families only, as otherwise between-sibling differentials may well pick up single-son effects. The hypothesis of no differential treatment corresponds to factor loadings being equal to one. Estimates of factor loadings which are larger (smaller) than unity would mean that intergenerational transmission matters more (less) for second sons compared with first sons.

Results are in Column (3) of Table 5. There is some variation in parameter estimates relative to Table 2 because now we are considering a different, much smaller, sample, i.e. only triplets. The two intergenerational loading factors for the second son are precisely estimated. The estimated loading factor associated with initial earnings indicates that there is stronger transmission to the second sons, +32 per cent compared with first sons, and the coefficient is statistically different from unity. Transmission of earnings growth is slightly weaker to second sons, -4 per cent compared to first sons. As a way to assess the joint (intercepts and slopes) significance of between-son differences, Figure 6 plots predicted intergenerational correlations for the two sons. At age 25 second sons are characterised by a level of the intergenerational correlation that is twice as large as that of first sons, reflecting the substantially stronger transmission of initial earnings to second sons. The difference shrinks rapidly with age, and by the age of 35 the point estimate of one son enters the confidence interval for the other, ruling out statistically significant differences. Thus, we conclude that there are only mild differences in intergenerational transmission between brothers, concentrated at young ages. This points to fathers transmitting more of their earnings to second sons, which may reflect parents' greater economic stability or greater experience in parenting for second son.

At first glance, stronger transmission to second sons may appear to contradict birth order studies finding that first born children do better. Our model, however, is not a model for which son does better, but a model for which son is more similar to the father in an earnings correlation sense. Our result may actually emerge from a situation in which poor families concentrate investments on first sons (compatible with findings in the birth order literature) which exhaust the resources available to second sons. This will make it more likely that second sonsbegin work in a low earnings quantile, thus resembling their fathers' earnings position more closely than their brothers' do. ${ }^{23}$

\footnotetext{
${ }^{23}$ We thank Gary Solon for suggesting this interpretation to us.
} 


\section{Conclusion}

We have shown that paternal earnings account for a substantive share of the overall correlation of permanent earnings between brothers. This is a much greater share than has been found in previous research that has used indirect decomposition methods. One implication is that policy interventions on social environments outside the family may have a limited impact on the inequality of long-term earnings. This is in line with the findings of Page and Solon (2003a and 2003b) that much of sibling correlations in the US is accounted for by the family rather than the neighbourhood. We provide evidence that lack of both life cycle effects and heterogeneous intergenerational transmission in previous studies explain the difference.

Another highlight from our research is that there are large life cycle effects in sibling correlations. We obtain estimates of the sibling correlations that follow a u-shaped profile between the ages of 25 and 48. On average, our estimates replicate the findings of previous research for Denmark in the same age range, but we show that the average masks significant variation over the life cycle. Observing, as we do, large sibling effects at the start of the life cycle may be particularly worrying in the presence of credit constraints that may be binding when young.

Having established that paternal earnings are important in determining sibling correlations, this raises further issues that can be addressed in the future. What are the determinants of the two components of sibling correlations identified in this paper? Endowments and social networks are two dimensions for future investigations. Assessing the importance of these factors is not new to the literature; however, looking at them using multiperson models of earnings dynamics similar to the ones of this paper may provide new insights on these long-standing issues. 


\section{Appendix}

Minimum Distance estimation of the model is based on imposing the moment restrictions implied by the model on empirical second moments estimated from the data.

Moment restrictions for the model of permanent earnings are provided below:

Father's covariance structure

$$
E\left(y_{i j t}^{F} y_{i j q}^{F}\right)=\left(\sigma_{\mu I}^{2}+\sigma_{\gamma I}^{2} A_{i t} A_{i q}+\sigma_{\mu \gamma I}\left(A_{i t}+A_{i q}\right)+\sigma_{\omega 0 F}^{2}+\sigma_{\phi F}^{2} A_{i t}\right) \pi_{t} \pi_{q}, \quad t \leq q .
$$

Son's covariance structure

$$
\begin{gathered}
E\left(y_{i j t}^{S b} y_{i j q}^{S b}\right)=\left(\left(\sigma_{\mu I}^{2}+\sigma_{\mu R}^{2}\right)+\left(\sigma_{\gamma I}^{2}+\sigma_{\gamma R}^{2}\right) A_{i t} A_{i q}+\left(\sigma_{\mu \gamma I}+\sigma_{\mu \gamma R}\right)\left(A_{i t}+A_{i q}\right)+\right. \\
\left.\sigma_{\omega 0 S b}^{2}+\sigma_{\phi S b}^{2} A_{i t}\right) \pi_{t} \pi_{q}, \quad t \leq q, \quad b=1,2
\end{gathered}
$$

Father-Son covariance structure

$$
E\left(y_{i j t}^{F} y_{k j q}^{S b}\right)=\left(\sigma_{\mu I}^{2}+\sigma_{\gamma I}^{2} A_{i t} A_{i q}+\sigma_{\mu \gamma I}\left(A_{i t}+A_{i q}\right)\right) \pi_{t} \pi_{q}, \quad b=1,2 .
$$

Son-Son covariance structure

$$
E\left(y_{i j t}^{S 1} y_{k j q}^{S 2}\right)=\left(\left(\sigma_{\mu I}^{2}+\sigma_{\mu R}^{2}\right)+\left(\sigma_{\gamma I}^{2}+\sigma_{\gamma R}^{2}\right) A_{i t} A_{i q}+\left(\sigma_{\mu \gamma I}+\sigma_{\mu \gamma R}\right)\left(A_{i t}+A_{i q}\right)\right) \pi_{t} \pi_{q}
$$

RG and RW parameters are identified by variation in age (in deviation from age 25). RW parameters are identified by individual earnings moments. Intergenerational RG parameters are identified by Father-Son earnings moments. RG sibling parameters are identified by Son-Son earnings moments, so that the difference between siblings moments and intergenerational moments identifies residual sibling parameters. Using parameter estimates we can decompose the total sibling correlation of permanent earnings into its intergenerational and residual sibling components over the life cycle, obtaining equation (10) of the main text:

$$
\rho^{S}(A)=\rho^{I}(A)+\rho^{R}(A) .
$$

where

$$
\rho^{I}(A)=\frac{\sigma_{\mu I}^{2}+\sigma_{\gamma I}^{2} A^{2}+2 \sigma_{\mu \gamma I} A}{\operatorname{var}(y(A))}
$$




$$
\rho^{R}(A)=\frac{\sigma_{\mu R}^{2}+\sigma_{\gamma R}^{2} A^{2}+2 \sigma_{\mu \gamma R} A}{\operatorname{var}(y(A))}
$$

and

$$
\begin{gathered}
\operatorname{var}(Y(A))=\left(\left(\sigma_{\mu I}^{2}+\sigma_{\mu R}^{2}\right)+\left(\sigma_{\gamma I}^{2}+\sigma_{\gamma R}^{2}\right) A^{2}+\left(\sigma_{\mu \gamma I}^{2}+\sigma_{\mu \gamma R}^{2}\right) 2 A+\sigma_{\omega 0 S b}^{2}+\sigma_{\phi S b}^{2} A\right) \\
b=1,2 .
\end{gathered}
$$

Within person moment restrictions for the member-specific AR(1) model are as follows:

$$
\begin{gathered}
E\left(v_{i j t}^{h} v_{i j q}^{h}\right)=\left(d(t=q=s) \eta_{c}^{d\left(s=t_{0}\right)} \sigma_{s h}^{2}+d(t=q>s)\left(\sigma_{\varepsilon h A}^{2}+\operatorname{var}\left(u_{i j t-1}\right) \rho_{h}^{2}\right)+\right. \\
\left.d(t \neq q)\left(E\left(u_{i j t-1} u_{i j q}\right) \rho_{h}\right)\right) \tau_{t} \tau_{q} .
\end{gathered}
$$

Thanks to the allowance for contemporaneous correlation of transitory shocks across different persons, the model yields restrictions on transitory earnings also for cross-member moments:

$$
\begin{gathered}
E\left(v_{i j t}^{h} v_{k j q}^{l}\right)=\sigma_{h l}\left(\frac{\left(1-\left(\rho_{h} \rho_{l}^{|t-q|}\right)^{P}\right)}{1-\rho_{h} \rho_{l}^{|t-q|}}\right)^{d(t \leq q)}\left(\frac{\left(1-\left(\rho_{l} \rho_{h}^{|t-q|}\right)^{P}\right)}{1-\rho_{l} \rho_{h}^{|t-q|}}\right)^{d(t>q)}, \\
h=F, S 1, S 2 ; l=S 1, S 2 ; h \neq l .
\end{gathered}
$$

where $P$ is the number of years the two family members are simultaneously observed in the data. 


\section{References}

Abowd, John M. and David Card. "On the Covariance Structure of Earnings and Hours Changes.” Econometrica,1989, 57(2), pp. 411-45.

Altonji, Joseph G. and Thomas A. Dunn. "Family Incomes and Labor Market Outcomes of Relatives.” In Ehrenberg, R., ed., Research in Labor Economics, Vol. 12, Greenwich CT: Jai Press, 1991, pp. 246-69.

Altonji, Joseph G., Anthony Smith and Ivan Vidangos. "Modeling Earnings Dynamics.", Econometrica, 81(4), 2013, pp. 1395-454.

Anti Nilsen, Øivind, Kjell Vaage, Arild Aakvik and Karl Jacobsen. "Intergenerational Earnings Mobility Revisited: Estimates Based on Lifetime Earnings.” Scandinavian Journal of Economics, 114(1), 2012, pp. 1-23.

Baadsgaard, Mikkel and Jarl Quitzau. "Danish Registers on Personal Income and Transfer Payments.” Scandinavian Journal of Public Health, 39(7), 2011, pp.103-105.

Baker, Michael. "Growth-Rate Heterogeneity and the Covariance Structure of Life-Cycle Earnings.”Journal of Labor Economics, 1997, 15(2), pp. 338-75.

Baker, Michael and Gary Solon. "Earnings Dynamics and Inequality among Canadian Men, 1976-1992: Evidence from Longitudinal Income Tax Records." Journal of Labor Economics, 2003, 21(2), pp. 267-88.

Becker, Gary S. and Nigel Tomes. "An Equilibrium Theory of the Distribution of Income and Intergenerational Mobility.” Journal of Political Economy 87 (6), 1979, pp. 1153-89.

Behrman, Jere R., Robert A. Pollak and Paul Taubman. "Parental Preferences and Provision for Progeny.” Journal of Political Economy, 1982, vol. 90(1), pp. 52-73.

Behrman, Jere R., Mark R. Rosenzweig and Taubman, Paul. "Endowments and the Allocation of Schooling in the Family and in the Marriage Market: The Twins Experiment." Journal of Political Economy, 1994, vol. 102(6), pp. 1131-74.

Behrman, Jere R., and Paul Taubman. "Birth Order, Schooling, and Earnings." Journal of Labor Economics, 1986, vol. 4(3), pp. S121-45.

Bingley, Paul, Lorenzo Cappellari and Niels Westergård-Nielsen. "Unemployment Insurance, Wage Dynamics and Inequality over the Life Cycle", Economic Journal, 2013, 123(568), pp 341-72.

Björklund, Anders and Markus Jännti. "Intergenerational Income Mobility and the Role of Family Background." in W. Salverda, B. Nolan and T. Smeeding, eds., The Oxford Handbook of Economic Inequality, Oxford: Oxford University Press, 2009, pp. 491521. 
Björklund, Anders and Markus Jännti. "How Important is Family Background for LaborEconomic Outcomes?” Labour Economics, 2012, 19(4), pp. 491-521.

Björklund, Anders, Markus Jäntti and Matthew J. Lindquist. "Family Background and Income during the Rise of the Welfare State: Brother Correlations in Income for Swedish Men Born 1932-1968” Journal of Public Economics, 2009, 93(5-6), pp. 671-80.

Björklund, Anders, Lena Lindahl and Matthew J. Lindquist. "What More Than Parental Income, Education and Occupation? An Exploration of What Swedish Siblings Get from Their Parents." The B.E. Journal of Economic Analysis \& Policy, Berkeley Electronic Press, vol. 10(1), 2010, Article 102.

Black, Sandra E. and Paul J. Devereux. "Recent Developments in Intergenerational Mobility." in O. Ashenfelter and D. Card, eds., Handbook of Labor Economics, Vol. 4A. Amsterdam: Elsevier Science, North Holland, 2011, pp. 1487-541 .

Black, Sandra E., Paul J. Devereux and Kjell G. Salvanes. "The More the Merrier? The Effect of Family Size and Birth Order on Children's Education.” The Quarterly Journal of Economics, vol. 120(2), 2005, pp. 669-700.

Blundell, Richard, Luigi Pistaferri and Itay Saporta-Eksten. "Consuption Inequality and Family Labor Supply.”, National Bureau of Economic Research, 2012, Working Paper 18445.

Bohlmark, Anders and Matthew J. Lindquist. "Life-Cycle Variations in the Association between Current and Lifetime Income: Replication and Extension for Sweden.” Journal of Labor Economics, 2006, 24(4), pp. 879-900.

Bonke, Jens, Martin D. Munk and Azhar Hussain. "Intergenerational Earnings Mobilities How Sensitive are They to Income Measures?” Journal of Income Distribution, 2009, 18(3-4).

Browning, Martin and Mette, Ejrnæs. "Heterogeneity in the Dynamics of Labor Earnings." Annual Review of Economics, 2013, vol. 5. Chamberlain, Gary. "Panel Data.", in Z. Griliches and M. Intriligator, eds., Handbook of Econometrics, Vol. 2, Amsterdam: Elsevier Science, North Holland, 1984, pp. 1248-318.

Grawe, Nathan D.. "Lifecycle Bias in Estimates of Intergenerational Earnings Persistence." Labour Economics, 2006, vol. 13(5), pp. 551-70.

Griliches, Zvi. "Sibling Models and Data in Economics: Beginnings of a Survey.” Journal of Political Economy, 1979, 87(5), pp. S37-S64.

Guvenen, Fatih. "Learning Your Earning: Are Labor Income Shocks Really Very Persistent?" American Economic Review, 2007, vol. 97(3), pp. 687-712. 
Haider, Stephen J.. "Earnings Instability and Earnings Inequality of Males in the United States: 1967-1991.” Journal of Labor Economics, 2001, 19(4), pp. 799-836.

Haider, Steven J. and Gary Solon. "Life-Cycle Variation in the Association between Current and Lifetime Earnings.” American Economic Review, 2006, 96(4), pp. 1308-20.

Hause, John C. "The Fine Structure of Earnings and the On-the-Job Training Hypothesis.", Econometrica, 1980, 48(4), pp.1013-29.

Hotz, Joseph, V. and Juan Pantano (2011) "Strategic Parenting, Birth Order and School Performance", unpublished manuscript.

Hryshko, Dmytro. "Labor Income Profiles are not Heterogeneous: Evidence from Income Growth Rates.” Quantitative Economics, 2012, vol.3, pp. 177-209.

Hyslop, Dean R. "Rising U.S. Earnings Inequality and Family Labor Supply: The Covariance Structure of Intrafamily Earnings.” American Economic Review, 2001, 91(4), pp. 75577.

Jenkins, Stephen J.. "Snapshots versus Movies: 'Lifecycle Biases' and the Estimation of Intergenerational Earnings Inheritance.” European Economic Review, 1987, 31(5), pp. 1149-58.

Lillard, Lee and Yoram Weiss. "Components of Variation in Panel Earnings Data: American Scientists, 1960-70.”, Econometrica, 1979, 47(2), pp. 437-59.

Lillard, Lee and Robert Willis. "Dynamic Aspects of Earning Mobility.", Econometrica, 1978, 46(5), pp. 985-1012.

MaCurdy, Thomas. E.. "The Use of Time Series Processes to Model the Error Structure of Earnings in a Longitudinal Data Analysis.”, Journal of Econometrics, 1982, 18(1), pp. 83-114.

Mazumder, Bhashkar. "Fortunate Sons: New Estimates of Intergenerational Mobility in the United States Using Social Security Earnings Data." Review of Economics and Statistics, 2005, 87(2), pp. 235-55.

Mazumder, Bhashkar. "Sibling Similarities and Economic Inequality in the US," Journal of Population Economics, 2008, 21(3), pp. 685-701.

Meghir, Costas and Luigi Pistaferri. "Earnings, Consumption, and Life Cycle Choices.”, in O. Ashenfelter and D. Card, eds., Handbook of Labor Economics, Vol. 4A. Amsterdam: Elsevier Science, North Holland, 2011, pp. .

Moffitt, Robert and Peter Gottschalk. "Trends in the Variances of Permanent and Transitory Earnings in the U.S. and Their Relation to Earnings Mobility.", Boston College Working Papers in Economics 444, Boston College Department of Economics, 1995 
Moffitt, Robert and Peter Gottschalk. "Trends in the Transitory Variance of Male Earnings: Methods and Evidence." Journal of Human Resources, 2012, 47(1), pp. 204-36.

Nybom, Martin and Jan Stuhler. "Heterogeneous Income Profiles and Life-Cycle Bias in Intergenerational Mobility Estimation.”, IZA DP No. 5697, 2011

Ostrovsky, Yuri “The Correlation of Spouses' Permanent and Transitory Earnings and Family Earnings Inequality in Canada” Labour Economics, 2012, 19(5), pp. 756-68.

Page, Marianne and Gary Solon. "Correlations between Sisters and Neighbouring Girls in their Subsequent Income as Adults.” Journal of Applied Econometrics, 2003, 18(5), pp. 545-62.

Page Marianne and Gary Solon. "Correlations between Brothers and Neighboring Boys in Their Adult Earnings: The Importance of Being Urban.” Journal of Labor Economics, 2003, 21(4), pp. 831-56.

Pedersen, Carsten Bøcker, Heine Gøtzsche, Jørgen Østrup Møller and Preben Bo Mortensen (2006) "The Danish Civil Registration System: A Cohort of Eight Million Persons", Danish Medical Bulletin, vol. 53(4), 2006, 441-449.

Solon, Gary. "Intergenerational Income Mobility in the United States" American Economic Review 82 (3), 1992, pp.393-408.

Solon, Gary, Mary Corcoran, Roger Gordon, and Deborah Laren. “A Longitudinal Analysis of Sibling Correlations in Economic Status.” Journal of Human Resources, 1991, 26(3), pp. 509-34

Solon, Gary. "Intergenerational Mobility in the Labor Market." in O. Ashenfelter and D. Card, eds., Handbook of Labor Economics, Vol. 3A. Amsterdam: Elsevier Science, North Holland, 1999, pp. 1761-800.

Zimmerman, David J. "Regression toward Mediocrity in Economic Stature." American Economic Review 82 (3), 1992, pp.409-429. 


\section{Table 1: Descriptive statistics}

\begin{tabular}{|c|c|c|c|c|c|c|c|}
\hline & & (1) Sam & without ec & s selection & (2) & timation sc & ple \\
\hline & & Father & Son 1 & Son2 & Father & Son 1 & Son2 \\
\hline \# Individuals & & 396736 & 396736 & 115509 & 326341 & 326341 & 88356 \\
\hline \# Observation & & 8112986 & 5193082 & 1409792 & 7103657 & 4557218 & 1157438 \\
\hline 1990 & Earnings & 367494 & 286872 & 269512 & 366484 & 290238 & 273853 \\
\hline & SD Earnings & 200849 & 137865 & 126391 & 167141 & 125580 & 118398 \\
\hline & Age & 44.7 & 27.9 & 27.0 & 44.8 & 27.9 & 27.0 \\
\hline 1995 & Earnings & 376226 & 296507 & 283422 & 373952 & 298807 & 286928 \\
\hline & SD Earnings & 220566 & 147595 & 137790 & 180687 & 134807 & 125366 \\
\hline & Age & 49.4 & 29.2 & 28.2 & 49.6 & 29.2 & 28.1 \\
\hline 2000 & Earnings & 394004 & 327994 & 312039 & 389313 & 329459 & 315138 \\
\hline & SD Earnings & 250858 & 188471 & 167531 & 188667 & 161141 & 146507 \\
\hline & Age & 52.1 & 30.8 & 29.6 & 52.2 & 30.8 & 29.6 \\
\hline 2005 & Earnings & 392516 & 370406 & 355919 & 386897 & 370352 & 357991 \\
\hline & SD Earnings & 246300 & 222133 & 195490 & 189057 & 178559 & 162501 \\
\hline & Age & 55.5 & 34.3 & 33.1 & 55.6 & 34.3 & 33.2 \\
\hline 2010 & Earnings & 402068 & 416365 & 401634 & 394428 & 414657 & 401868 \\
\hline & SD Earnings & 293636 & 303068 & 268377 & 205427 & 211435 & 194422 \\
\hline & Age & 56.7 & 37.9 & 36.8 & 56.8 & 37.9 & 36.9 \\
\hline
\end{tabular}


Variance of initial earnings

$\sigma_{\mu I}^{2}$ (Intergenerational)

$\sigma_{\mu R}^{2}$ (Residual Sibling)

0.0339

0.0015

0.0243

0.0029

Variance of earnings growth rates

$\sigma_{\gamma I}^{2}$ (Intergenerational)

$0.0002 \quad 0.00001$

$\sigma_{\gamma R}^{2}($ Residual Sibling)

0.0002

0.00001

Covariance

$\sigma_{\mu \gamma I}($ Intergenerational)

$-0.0014 \quad 0.0001$

$\sigma_{\mu \gamma R}($ Residual Sibling)

$-0.0018$

0.0002

Idiosyncratic component

Variance of initial earnings

$\begin{array}{lll}\sigma_{\omega 0 F}^{2}(\text { Father }) & 0.0697 & 0.0043 \\ \sigma_{\omega 0 S 1}^{2}(\text { Son 1) } & 0.0711 & 0.0051 \\ \sigma_{\omega 0 S 2}^{2}(\text { Son 2) } & 0.0531 & 0.0048\end{array}$

Variance of shocks

$\sigma_{\phi F}^{2}$ (Father)

$\begin{array}{ll}0.0021 & 0.0006\end{array}$

$\sigma_{\phi S 1}^{2}($ Son 1)

0.0007

$\sigma_{\phi S 2}^{2}($ Son 2)

0.0071

0.0009 
Table 3: Estimates of member-specific AR(1) parameters of transitory earnings

\begin{tabular}{|c|c|c|c|c|c|c|}
\hline & \multicolumn{2}{|c|}{ Father } & \multicolumn{2}{|c|}{ Son 1} & \multicolumn{2}{|c|}{ Son 2} \\
\hline & Coeff. & S.E. & Coeff. & S.E. & Coeff. & S.E. \\
\hline$\sigma_{\varepsilon h}^{2}($ Baseline variance $)$ & 0.2847 & 0.0355 & 0.2474 & 0.0254 & 0.2309 & 0.0246 \\
\hline \multicolumn{7}{|l|}{ Age splines } \\
\hline $26-30$ & -0.1024 & 0.0476 & -0.1357 & 0.0037 & -0.1392 & 0.0065 \\
\hline $31-35$ & -0.0286 & 0.0176 & -0.0501 & 0.0034 & -0.0644 & 0.0066 \\
\hline $36-40$ & -0.0263 & 0.0111 & -0.0031 & 0.0040 & -0.0002 & 0.0082 \\
\hline $41-45$ & 0.0010 & 0.0127 & -0.0348 & 0.0093 & -0.0134 & 0.0197 \\
\hline $46-51$ & -0.0199 & 0.0055 & -0.0301 & 0.0133 & -0.1052 & 0.0483 \\
\hline $52-60$ & 0.0591 & 0.0029 & & & & \\
\hline$\rho_{h}($ Autocorrelation coefficient $)$ & 0.5136 & 0.0102 & 0.5141 & 0.0034 & 0.5213 & 0.0055 \\
\hline$\sigma_{s h}^{2}($ Baseline initial condition $)$ & 0.2558 & 0.0255 & 0.4115 & 0.0419 & 0.4126 & 0.0428 \\
\hline \multicolumn{7}{|l|}{$\begin{array}{l}\lambda_{c}(\text { Initial condition shifter for left- } \\
\text { censored cohorts, } 1953-55=1)\end{array}$} \\
\hline $1935-37$ & 1.3514 & 0.1982 & & & & \\
\hline $1938-40$ & 1.4657 & 0.1895 & & & & \\
\hline $1941-43$ & 1.3005 & 0.1585 & & & & \\
\hline $1944-46$ & 1.0929 & 0.1257 & & & & \\
\hline $1947-49$ & 0.8896 & 0.0972 & & & & \\
\hline $1950-52$ & 0.9384 & 0.0961 & & & & \\
\hline \multicolumn{7}{|l|}{$\sigma_{h l}($ Between-person covariance $)$} \\
\hline Father & & & 0.0027 & 0.0003 & 0.0030 & 0.0003 \\
\hline Son1 & & & & & 0.0066 & 0.0007 \\
\hline
\end{tabular}


Table 4: Estimates of period-specific loading factors

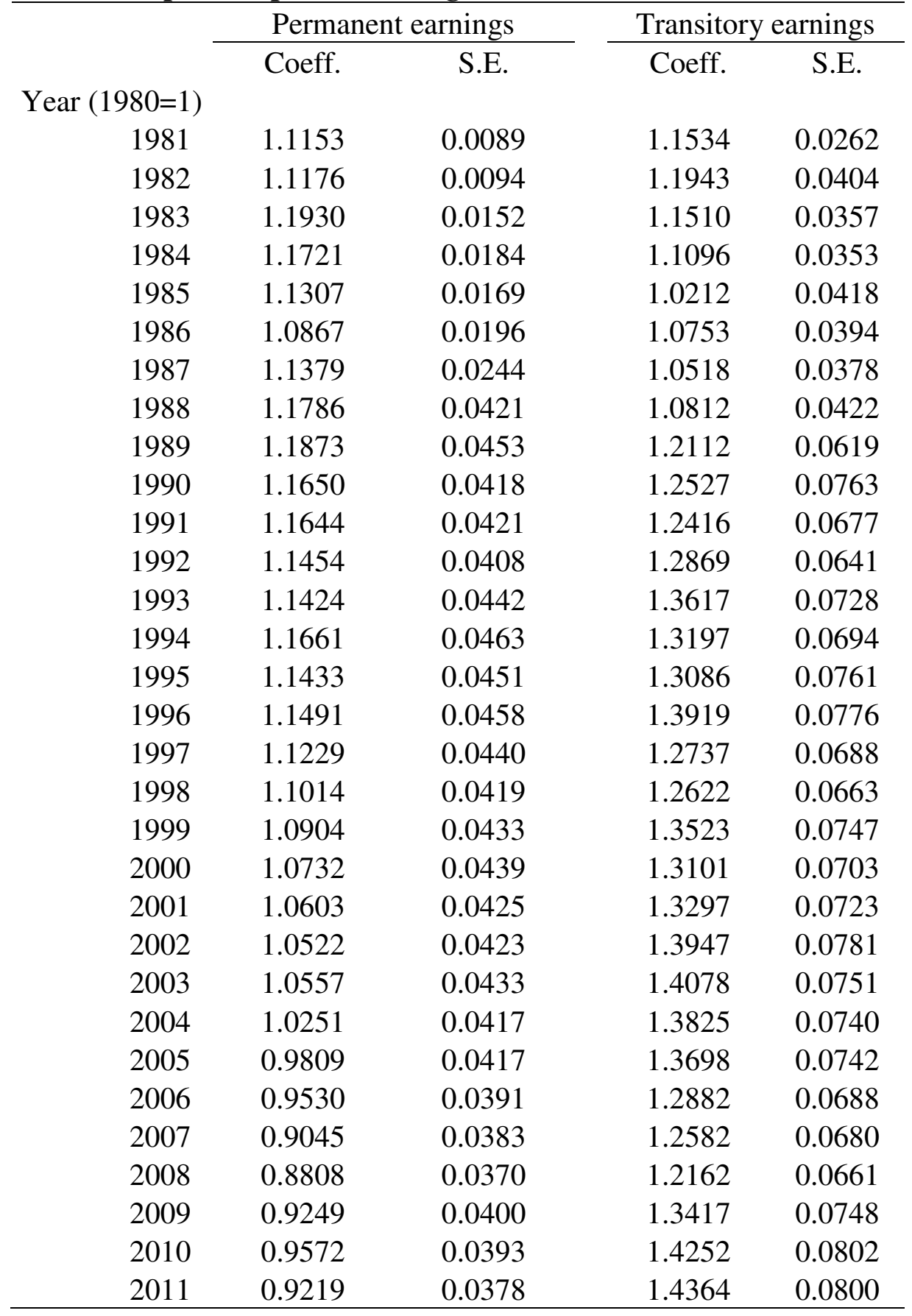


Table 5: Estimates of parameters of permanent earnings from nested models

(1) No life cycle effects

(2) Intergenerational only

Coeff.

Shared components

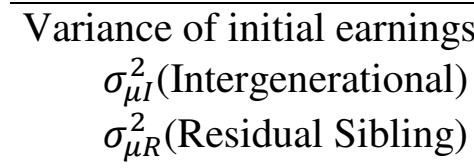

Variance of earnings growth rates

$\sigma_{\gamma I}^{2}$ (Intergenerational)

$\sigma_{\gamma R}^{2}($ Residual Sibling $)$

Covariance

$\sigma_{\mu \gamma I}($ Intergenerational $)$

$\sigma_{\mu \gamma R}($ Residual Sibling)

Idiosyncratic component

\begin{tabular}{|c|c|c|c|c|c|}
\hline \multirow{6}{*}{$\begin{array}{l}0.0127 \\
0.0070\end{array}$} & 0.0008 & 0.0390 & 0.0021 & & \\
\hline & & & & 0.0542 & 0.0040 \\
\hline & & 0.0002 & 0.00001 & & \\
\hline & & & & 0.0003 & 0.00002 \\
\hline & & -0.0017 & 0.0001 & & \\
\hline & & & & -0.0030 & 0.0002 \\
\hline
\end{tabular}

\begin{tabular}{llllll}
0.0781 & 0.0022 & 0.0666 & 0.0046 & & \\
0.0616 & 0.0048 & 0.0627 & 0.0046 & 0.0708 & 0.0054 \\
0.0477 & 0.0044 & 0.0469 & 0.0045 & 0.0518 & 0.0045 \\
& & & & & \\
& & 0.0020 & 0.0006 & & \\
& & 0.0071 & 0.0007 & 0.0053 & 0.0006 \\
& & 0.0079 & 0.0008 & 0.0063 & 0.0007 \\
\hline
\end{tabular}


Table 6: Estimates of parameters of permanent earnings by presence of sisters and with differential intergenerational transmission between brothers

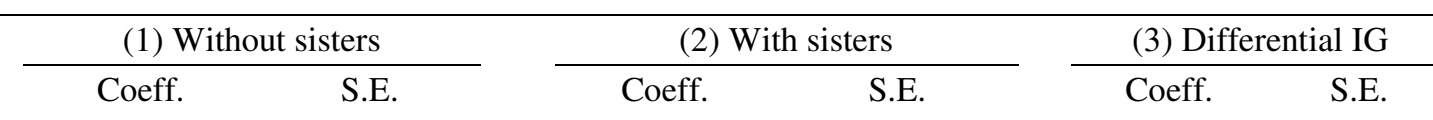

Shared components

\begin{tabular}{|c|c|c|c|c|c|c|}
\hline \multicolumn{7}{|l|}{ Variance of initial earnings } \\
\hline$\sigma_{\mu I}^{2}($ Intergenerational $)$ & 0.0333 & 0.0021 & 0.0322 & 0.0009 & 0.0319 & 0.0015 \\
\hline$\delta_{\mu}$ (Intergenerational loading Son 2) & & & & & 1.3212 & 0.0188 \\
\hline$\sigma_{\mu R}^{2}($ Residual Sibling $)$ & 0.0188 & 0.0034 & 0.0418 & 0.0026 & 0.0353 & 0.0026 \\
\hline \multicolumn{7}{|l|}{ Variance of earnings growth rates } \\
\hline$\sigma_{\gamma I}^{2}($ Intergenerational $)$ & 0.0001 & 0.00001 & 0.0002 & 0.00001 & 0.0002 & 0.00001 \\
\hline$\delta_{\gamma}$ (Intergenerational loading Son 2) & & & & & 0.9689 & 0.0046 \\
\hline$\sigma_{\gamma R}^{2}($ Residual Sibling $)$ & 0.0001 & 0.00002 & 0.0002 & 0.00001 & 0.0002 & 0.00001 \\
\hline \multicolumn{7}{|l|}{ Covariance } \\
\hline$\sigma_{\mu \gamma I}($ Intergenerational $)$ & -0.0014 & 0.0001 & -0.0013 & 0.00004 & -0.0015 & 0.0001 \\
\hline$\sigma_{\mu \gamma R}($ Residual Sibling $)$ & -0.0014 & 0.0002 & -0.0029 & 0.0002 & -0.0022 & 0.0001 \\
\hline \multicolumn{7}{|l|}{ Idiosyncratic component } \\
\hline \multicolumn{7}{|l|}{ Variance of initial earnings } \\
\hline$\sigma_{\omega 0 F}^{2}$ (Father) & 0.0740 & 0.0048 & 0.0581 & 0.0035 & 0.0532 & 0.0051 \\
\hline$\sigma_{\omega 0 S 1}^{2}($ Son 1$)$ & 0.0726 & 0.0073 & 0.0777 & 0.0039 & 0.0859 & 0.0054 \\
\hline$\sigma_{\omega 0 S 2}^{2}($ Son 2$)$ & 0.0459 & 0.0057 & 0.0650 & 0.0060 & 0.0570 & 0.0049 \\
\hline \multicolumn{7}{|l|}{ Variance of shocks } \\
\hline$\sigma_{\phi F}^{2}($ Father $)$ & 0.0013 & 0.0007 & 0.0039 & 0.0005 & 0.0045 & 0.0006 \\
\hline$\sigma_{\phi S 1}^{2}($ Son 1$)$ & 0.0063 & 0.0009 & 0.0089 & 0.0006 & 0.0102 & 0.0011 \\
\hline$\sigma_{\phi S 2}^{2}($ Son 2$)$ & 0.0061 & 0.0009 & 0.0118 & 0.0012 & 0.0118 & 0.0012 \\
\hline
\end{tabular}


Table 7: Decompositions of the sibling correlation using the approaches of previous research with and without IGE heterogeneity

Coeff. $\quad$ S.E.

$\%$

Decompositions with homogeneous IGE

Solon (1999) decomposition

$\operatorname{var}(a)$

$0.2358 \quad 0.0010$

$\operatorname{var}(f)$

$0.0550 \quad 0.0010$

$I G E$

$0.0757 \quad 0.0015$

$r^{S}$

$0.1892 \quad 0.0034$

Share of $r^{S}$ explained by $y_{j}^{F}$

Sequential conditioning
$\operatorname{var}(a)$ after conditioning on $y_{j}^{F}$
0.2359
0.0010
$\operatorname{var}(f)$ after conditioning on $y_{j}^{F}$
0.0527
0.0010
$r^{S}$ after conditioning on $y_{j}^{F}$
$0.1828 \quad 0.0034$

Share of $r^{S}$ explained by $y_{j}^{F}$

Decompositions with heterogeneous IGE

$$
\begin{aligned}
& \operatorname{var}(a) \\
& I G E \\
& \operatorname{var}(I G E) \\
& \operatorname{var}(\xi) \\
& r^{S}
\end{aligned}
$$

$\operatorname{var}(I G E)$

0.2354

0.0010

0.0912

0.0016

0.0307

0.0011

0.0422

0.0010

Share of $r^{S}$ explained by $y_{j}^{F}$

$0.1953 \quad 0.0034$

Assuming stationarity

Without assuming stationarity $\left(\operatorname{var}\left(y_{j}^{F}\right)=0.3824\right)$ 
Figure 1: Number of observations by type of family member, year of birth and age
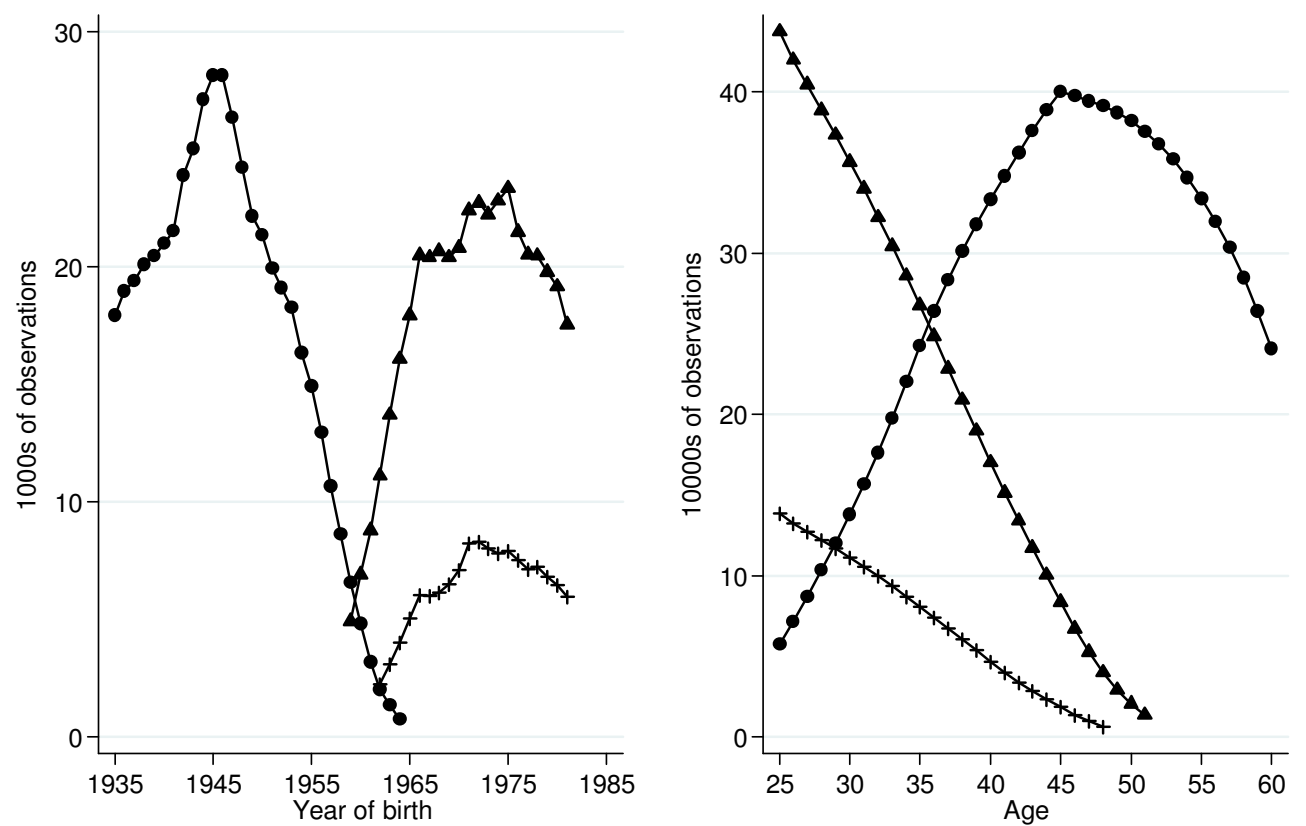

$$
\longrightarrow \text { Father } \longrightarrow \text { Son1 } \longrightarrow \text { Son2 }
$$


Figure 2: Intergenerational and sibling correlations of raw earnings
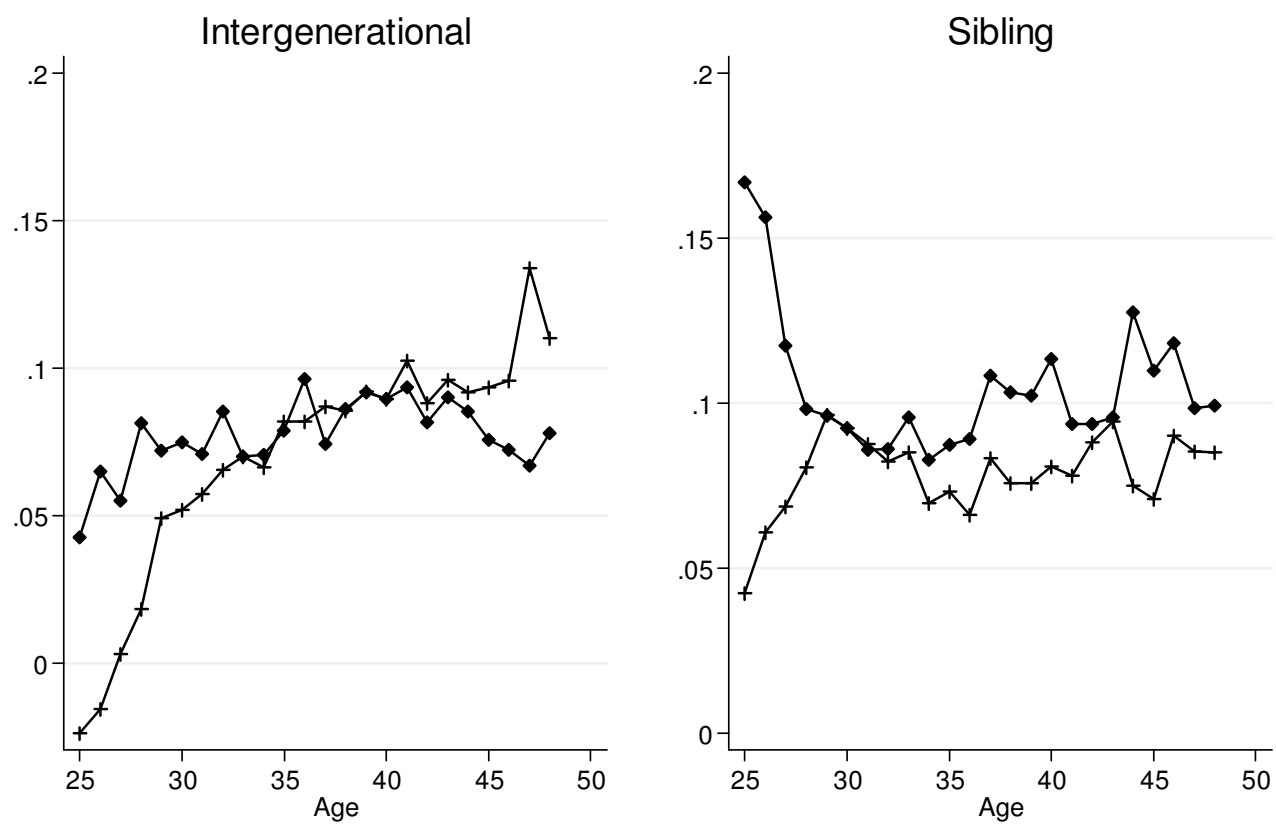

Same age

Fixed age 
Figure 3: Decomposition of sibling correlation of permanent earnings

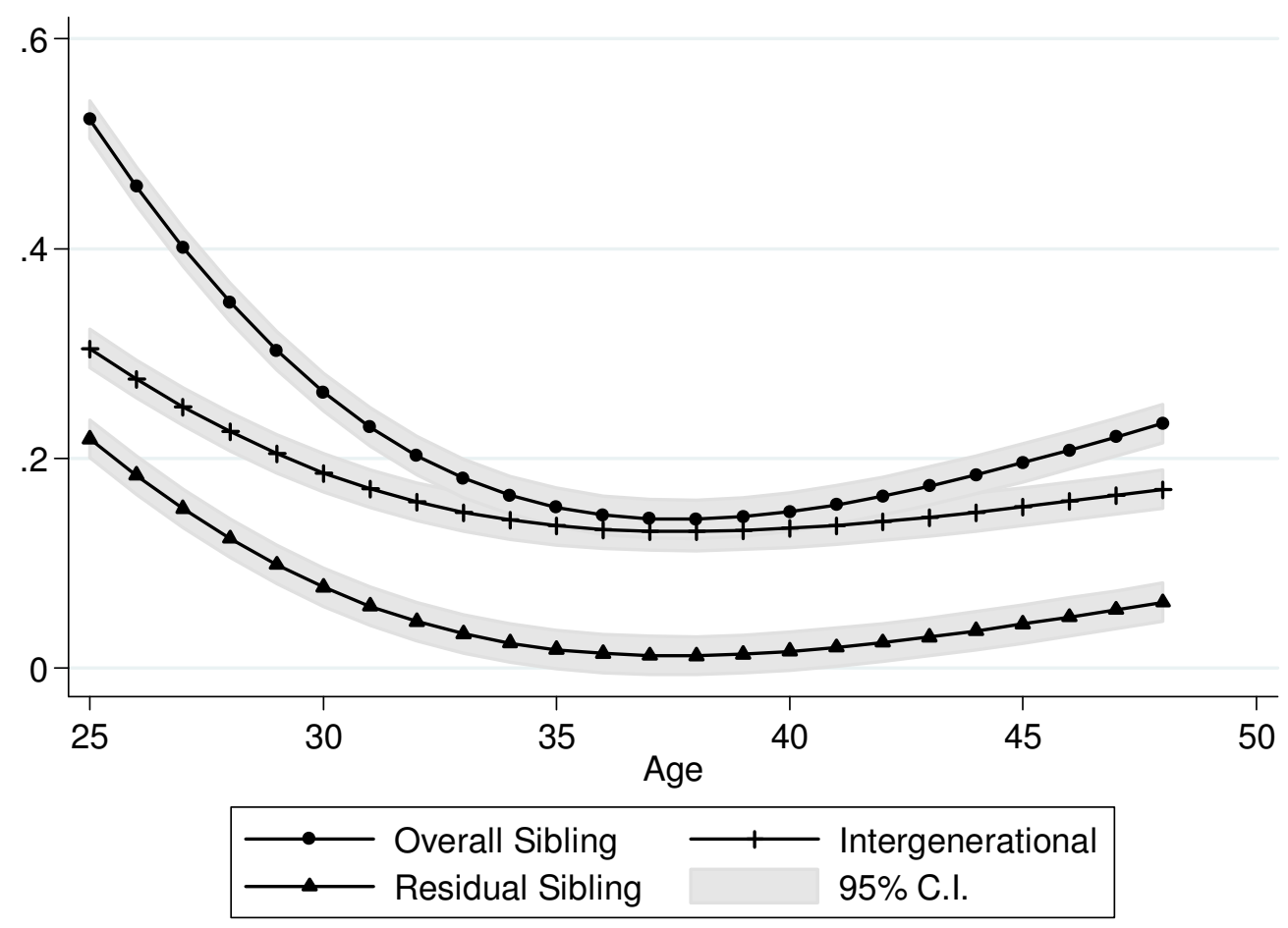


Figure 4: Comparison of intergenerational and overall sibling correlations of permanent earnings between full and nested models
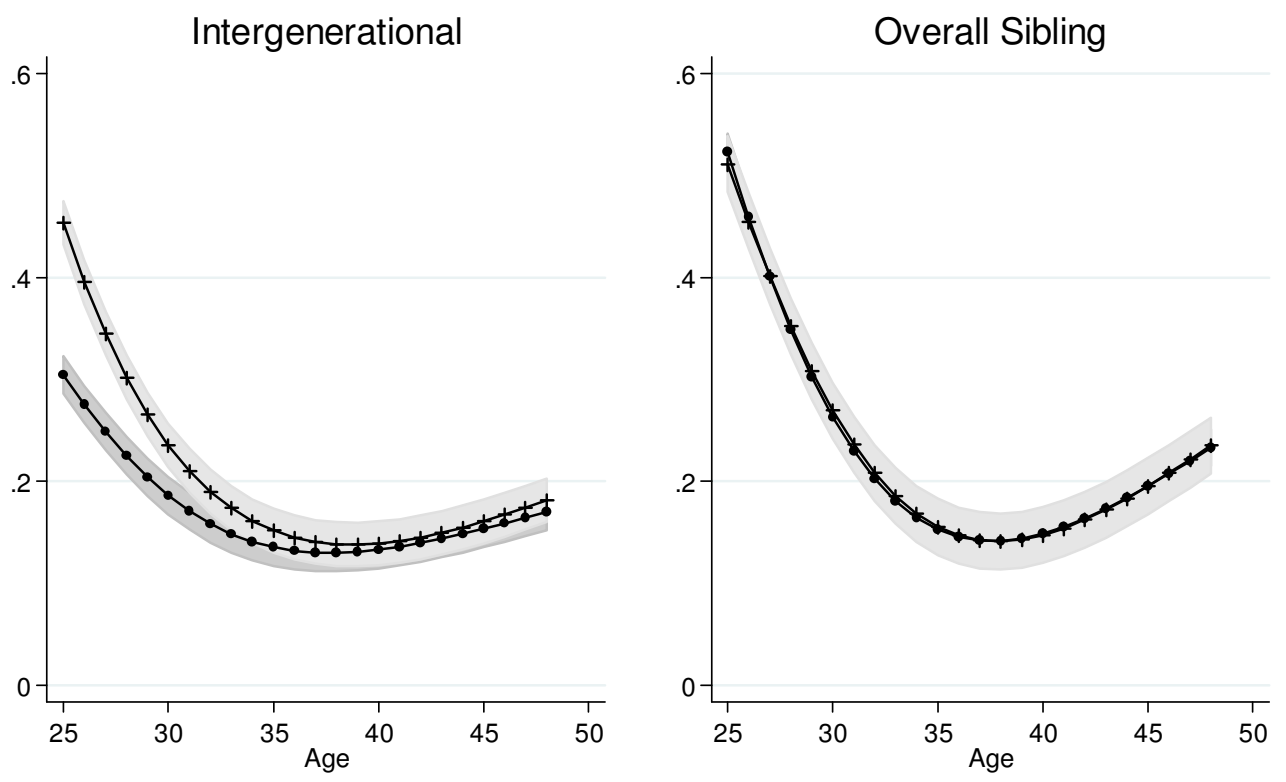

$\longrightarrow$ Full model $\begin{aligned} & \longrightarrow \\ & 95 \% \text { C.I. }\end{aligned}$


Figure 5: Decomposition of sibling correlations of permanent earnings by presence of sisters
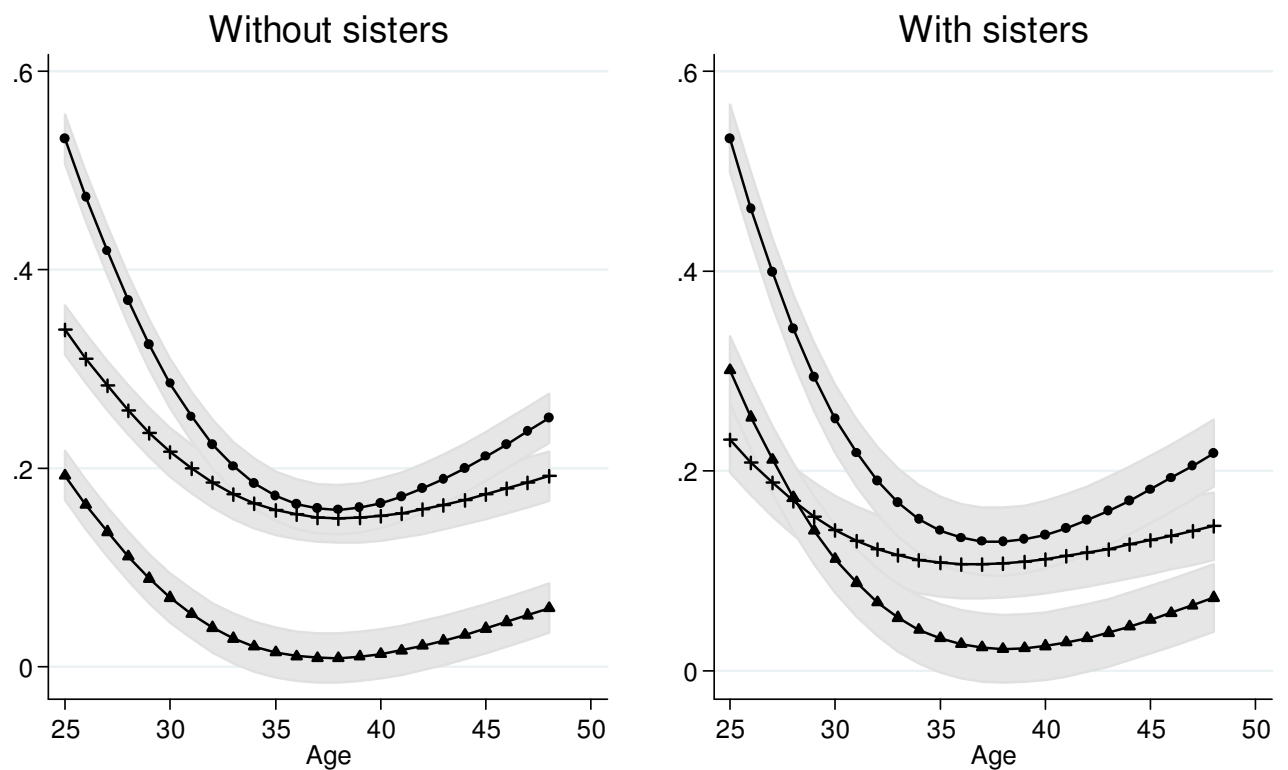

$\begin{array}{ll}\longrightarrow & \text { Overall Sibling } \longrightarrow \text { Intergenerational correlation } \\ \longrightarrow & \text { Residual Sibling } \\ 95 \% \text { C.I. }\end{array}$


Figure 6: Intergenerational correlations of permanent earnings from model with differential transmission - Triplets only sample

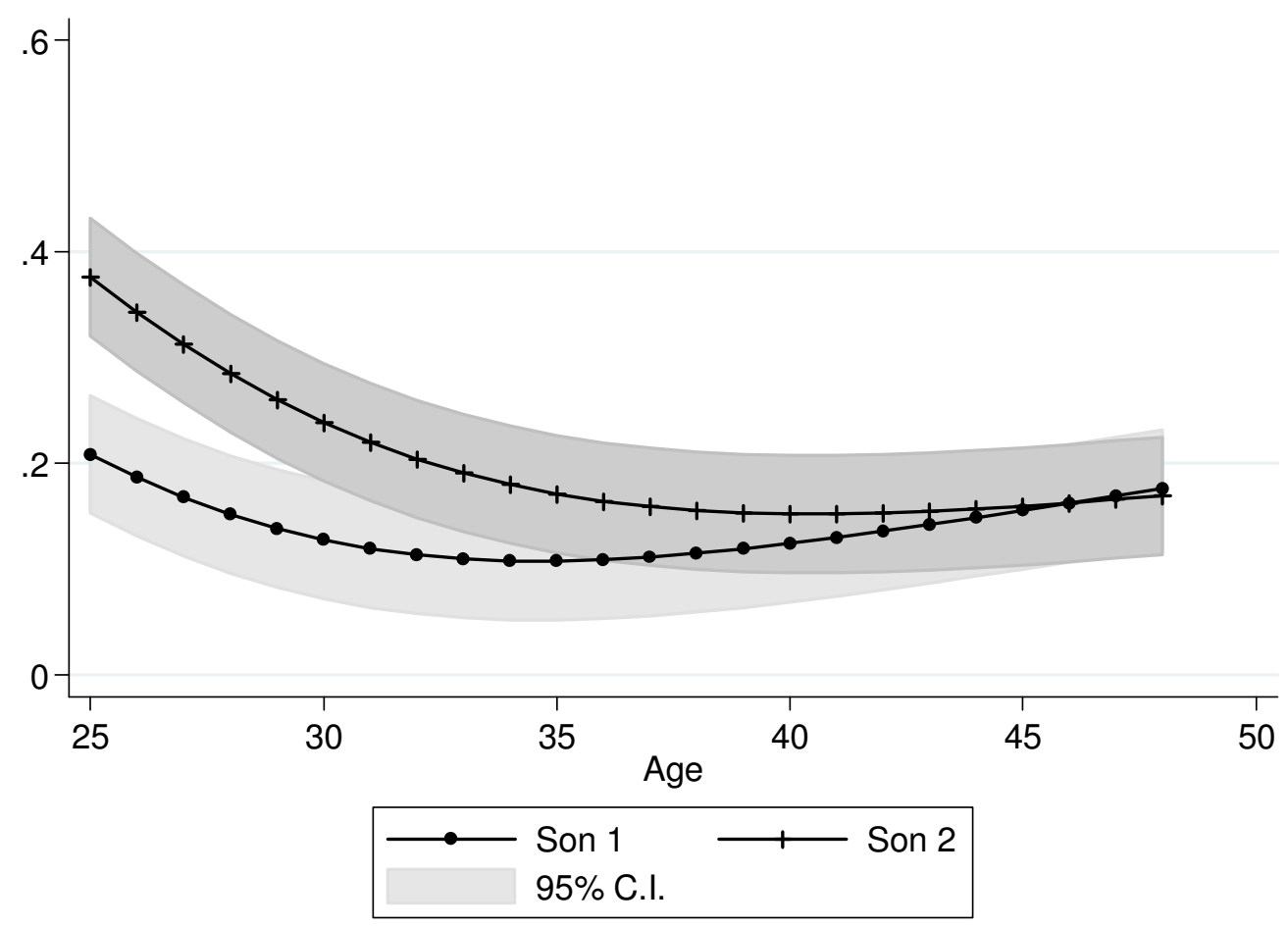




\section{Working Paper del Dipartimento di Economia e Finanza}

1. L. Colombo, H. Dawid, Strategic Location Choice under Dynamic Oligopolistic Competition and Spillovers, Novembre 2013.

2. M. Bordignon, M. Gamalerio, G. Turati, Decentralization, Vertical Fiscal Imbalance, and Political Selection, Novembre 2013.

3. M. Guerini, Is the Friedman Rule Stabilizing? Some Unpleasant Results in a Heterogeneous Expectations Framework, Novembre 2013.

4. E. Brenna, C. Di Novi, Is caring for elderly parents detrimental to women's mental health? The influence of the European North-South gradient, Novembre 2013.

5. F. Sobbrio, Citizen-Editors' Endogenous Information Acquisition and News Accuracy, Novembre 2013.

6. P. Bingley, L. Cappellari, Correlation of Brothers Earnings and Intergenerational Transmission, Novembre 2013. 